OPEN ACCESS

Edited by: Mario Pezzotti,

University of Verona, Italy

Reviewed by:

Serge Delrot,

University of Bordeaux, France Cristos Xiloyannis,

University of Basilicata, Italy

*Correspondence:

Matthew Gilliham

matthew.gilliham@adelaide.edu.au

Specialty section:

This article was submitted to

Plant Physiology,

a section of the journal

Frontiers in Plant Science

Received: 19 December 2015

Accepted: 13 April 2016

Published: 29 April 2016

Citation:

Hocking B, Tyerman SD, Burton RA and Gilliham M (2016) Fruit Calcium:

Transport and Physiology.

Front. Plant Sci. 7:569.

doi: 10.3389/fpls.2016.00569

\section{Fruit Calcium: Transport and Physiology}

\author{
Bradleigh Hocking 1,2, Stephen D. Tyerman ${ }^{1}$, Rachel A. Burton² and Matthew Gilliham ${ }^{1 *}$ \\ ${ }^{1}$ Plant Transport and Signaling Laboratory, ARC Centre of Excellence in Plant Energy Biology, School of Agriculture, Food \\ and Wine, Waite Research Institute, University of Adelaide, Glen Osmond, SA, Australia, ${ }^{2}$ ARC Centre of Excellence in Plant \\ Cell Walls, School of Agriculture, Food and Wine, Waite Research Institute, University of Adelaide, Glen Osmond, SA, \\ Australia
}

Calcium has well-documented roles in plant signaling, water relations and cell wall interactions. Significant research into how calcium impacts these individual processes in various tissues has been carried out; however, the influence of calcium on fruit ripening has not been thoroughly explored. Here, we review the current state of knowledge on how calcium may impact the development, physical traits and disease susceptibility of fruit through facilitating developmental and stress response signaling, stabilizing membranes, influencing water relations and modifying cell wall properties through crosslinking of de-esterified pectins. We explore the involvement of calcium in hormone signaling integral to the physiological mechanisms behind common disorders that have been associated with fruit calcium deficiency (e.g., blossom end rot in tomatoes or bitter pit in apples). This review works toward an improved understanding of how the many roles of calcium interact to influence fruit ripening, and proposes future research directions to fill knowledge gaps. Specifically, we focus mostly on grapes and present a model that integrates existing knowledge around these various functions of calcium in fruit, which provides a basis for understanding the physiological impacts of sub-optimal calcium nutrition in grapes. Calcium accumulation and distribution in fruit is shown to be highly dependent on water delivery and cell wall interactions in the apoplasm. Localized calcium deficiencies observed in particular species or varieties can result from differences in xylem morphology, fruit water relations and pectin composition, and can cause leaky membranes, irregular cell wall softening, impaired hormonal signaling and aberrant fruit development. We propose that the role of apoplasmic calcium-pectin crosslinking, particularly in the xylem, is an understudied area that may have a key influence on fruit water relations. Furthermore, we believe that improved knowledge of the calcium-regulated signaling pathways that control ripening would assist in addressing calcium deficiency disorders and improving fruit pathogen resistance.

Keywords: calcium, fruit ripening, xylem, pectin, water

\footnotetext{
Abbreviations: $\mathrm{ABA}$, abscisic acid; $\mathrm{Ca}^{2+}$, Calcium ion; $\mathrm{CEC}$, Cation exchange capacity; GA, Gibberellic acid; IAA, Indole acetic acid; $\mathrm{K}^{+}$, Potassium ion; OGA, Oligogalacturonide; PME, Pectin methyl-esterase; $\mathrm{R}_{\mathrm{h}}$, hydraulic resistance; WAK, Wall
} associated kinase. 


\section{INTRODUCTION}

Fruit are economically important plant organs that face unique challenges in terms of calcium nutrition and physiology. Fruit are architecturally isolated; their supply of water and nutrients changes during fruit development; they often have low rates of transpiration and have low xylem transport rates when compared with the rest of the plant, which limits fruit calcium delivery. We describe how these unique circumstances can create a situation in which calcium deficiencies can easily arise, leading to numerous disorders that impact fruit development and reduce crop quality. Although the strict botanical definition of fruit includes wheat grain and bean pods we mostly restrict ourselves in this review to discussing the multifaceted role of calcium in the flesh-rich seed-associated structures that are commonly referred to as fruit. In particular, this review often uses the role of calcium in grape, tomato, and kiwifruit as a model systems for understanding fruit calcium physiology. Much of our current knowledge on calcium signaling in plants is drawn from specific cell-types such as the guard cell or pollen tube. Different tissues and cell types possess their own protein network, developmental programming and physiology (Henderson and Gilliham, 2015); fruit are not guard cells, mesophyll tissue or pollen tubes - they differ in how they develop and how they respond to stress. Therefore, despite deficiency and toxicity symptoms often being most noticeable in fruit, generally we have a poor understanding of the physiological roles of calcium in fruit development.

The irreplaceable nature of the calcium ion $\left(\mathrm{Ca}^{2+}\right)$ as a signal transduction agent, and in cell wall polysaccharide interactions is undisputed; it is through these processes that calcium is central to stress responses, cell wall growth and remodeling, and to plant tissue development (Dodd et al., 2010; Hepler and Winship, 2010; Kudla et al., 2010; Gilliham et al., 2011b). As $\mathrm{Ca}^{2+}$ is such a biologically active ion its concentration and transport must be tightly controlled within plant tissue down to the level of cellular and extracellular compartments. If tissue calcium concentration is high, this can result in cellular toxicity, in overly rigid cell walls and in developmental abnormalities (Conn et al., 2011; Cybulska et al., 2011). When calcium supply is low or transport is disturbed, local calcium deficiencies result. This can lead to membrane breakdown and/or cell wall failure; in fruit this has been proposed to result in disorders such as blossom end rot (de Freitas and Mitcham, 2012). Whether this is the cause of such a disorder or whether calcium deficiency is a result of this condition has been recently debated (de Freitas et al., 2014; Saure, 2014); further insights into how cell wall calcium can influence tissue integrity are provided here.

The cell wall properties of fruit epidermal cell layers are important determinants of pathogen susceptibility. Fruit cell walls are pectin rich, and calcium-pectin cross-links are a major factor in determining the physical and structural properties of fruit. The cell wall is also the source of pectin derived OGAs that elicit pathogen defense responses (Decreux and Messiaen, 2005); cytosolic $\mathrm{Ca}^{2+}$ signaling also occurs during defense responses (Dodd et al., 2010), so the interactions between calcium in the cell wall and its cytosolic signaling role warrants further investigation from a fruit-pathogen susceptibility perspective. Treatment of some fruit with calcium-containing sprays is a routine horticultural practice, which can improve cell integrity and disease resistance (Manganaris et al., 2005; Dayod et al., 2010), demonstrating the importance of calcium in determining fruit quality at harvest and improving post-harvest traits. Here, we review the field, and nominate what are the most pressing research questions in this area.

Hormonal controls on cell division and expansion are active in the development of fruit. Many of these phytohormonal pathways utilize changes in cytoplasmic calcium concentration $\left(\left[\mathrm{Ca}^{2+}\right]_{\text {cyt }}\right)$ as a secondary signal messenger (e.g., ABA, jasmonic acid, auxin, GA, ethylene, brassinosteroids, and cytokinins; Fortes et al., 2015). Therefore, the reliance upon $\mathrm{Ca}^{2+}$ as a signaling element in a tissue with low and variable calcium supply has been said to create physiological disorders during development, such as blossom end rot in tomatoes (de Freitas et al., 2012). The case for calcium nutrition being an important consideration in establishing normal fruit development and optimizing stress responses is made here. As it is a phloem immobile nutrient, calcium is mainly reliant on transpirational water flow for its accumulation within fruit; however, calcium can regulate water flow through modification of aquaporin activity and cell wall properties that affect cell wall permeability to water so calcium has the potential to affect its own delivery locally (Gilliham et al., 2011b). The influence of calcium in pectin modification and micro-domain gel formation is also a potential source of influencing xylem water transport, water relations and calcium delivery (Zsivanovits et al., 2004). Therefore, the complex relationship between calcium, water, cell walls and signaling pathways make calcium a significant player in fruit physiology and development worthy of further attention.

\section{FRUIT CALCIUM TRANSPORT}

Fruit calcium nutrition is dependent upon the physical and molecular pathways of water and calcium delivery, and the impact that calcium signaling can have on cell wall interactions, transpiration, and water transport. The major factors that influence calcium delivery and distribution in aerial tissues include: the rate of xylem water mass flow (as $\mathrm{Ca}^{2+}$ is virtually phloem immobile), the competition between ions for binding sites in xylem vessel walls and pit membranes (including $\mathrm{H}^{+}$, making $\mathrm{pH}$ an important factor), formation of lowly soluble or insoluble complexes (e.g., calcium oxalate) and cellular water/ionic transport mechanisms (Franceschi and Nakata, 2005; Saure, 2005; Gilliham et al., 2011b). Calcium concentration in different cellular compartments can impact water transport processes via membrane-delimited pathways. For instance, increases in $\left[\mathrm{Ca}^{2+}\right]_{\text {cyt }}$ can decrease water transport through aquaporins (Alleva et al., 2006; Verdoucq et al., 2008). This has been proposed to affect the relative contribution of apoplasmic and symplasmic water flow and the magnitude of calcium delivery (Gilliham et al., 2011b), with symplastic pathways having a lower capacity for long distance $\mathrm{Ca}^{2+}$ movement. 


\section{Long-Distance Calcium Transport}

The link between water and calcium transport is particularly apparent when examining sink organs with relatively low transpiration rates, such as those that typically occur in fruit (Figure 1). At fruitset the transpiration rate of fruit is at its highest, for instance in kiwifruit this can be as high as $2.3 \mathrm{mmol}$ $\mathrm{m}^{-2} \mathrm{~s}^{-1}$, but this quickly declines to almost a tenth of this value later in development, whereas leaf transpiration is maintained greater than $10 \mathrm{mmol} \mathrm{m}^{-2} \mathrm{~s}^{-1}$ (Montanaro et al., 2014). It is at these early stages of fruit development that most $\mathrm{Ca}^{2+}$ is delivered to fruit (Montanaro et al., 2012a,b). In most species the delivery of water, sugar, and basic nutritional inputs during the later stages of fruit ripening occurs largely via the phloem (Drazeta et al., 2004; Rogiers et al., 2006b; Choat et al., 2009). As $\mathrm{Ca}^{2+}$ has low phloem mobility, calcium accumulation in aerial sink organs such as fruit is dependent upon its delivery by the xylem (Rogiers et al., 2000; Drazeta et al., 2004). The low phloem mobility of $\mathrm{Ca}^{2+}$ can create a situation that leads to localized calcium deficiencies in fruit. The relationship between calcium accumulation, fruit transpiration, and environmental variables is exemplified by observations made in kiwifruit (Montanaro et al., 2014). In kiwifruit, both phloem and xylem appear to contribute to fruit hydration during late development, but their relative contributions are affected by environmental conditions (Clearwater et al., 2012). Under high vapor pressure deficit, kiwifruit calcium accumulation is coupled to transpiration; under low vapor pressure deficit, lower transpiration and fruit water uptake occurs, with calcium accumulation instead more closely coupled with fruit growth rates (Montanaro et al., 2015).

Calcium accumulation in tomato fruit has been shown to be dependent on rates of xylem sap flow, influenced by transpiration and growth rates (Ho et al., 1993; de Freitas et al., 2014). The strength of other calcium sinks in the plant can affect calcium accumulation in the tomato, and may lead to calcium related physiological disorders such as blossom end rot (Ho and White, 2005). ABA treatment of whole plants reduced leaf peduncle xylem sap flow rate and leaf calcium uptake whilst increasing fruit peduncle xylem sap flow rate and fruit calcium uptake; these fruit demonstrated lower susceptibility to development of blossom end rot (de Freitas et al., 2014). However, accumulation of ionic nutrients in fruit is determined not only by water import rates, but also by their relative prevalence and mobility in the phloem and xylem. Unlike, $\mathrm{Ca}^{2+}$, which is only xylem mobile, $\mathrm{K}^{+}$is both xylem and phloemmobile, with $\mathrm{K}^{+}$concentrations in the phloem being up to ten times that found in the xylem (Hocking, 1980). Grape berry potassium accumulation occurs throughout berry development, reaching a maximum uptake rate during early post-veraison with uptake continuing throughout ripening (Rogiers et al., 2006b). In contrast, calcium content (i.e., Ca per berry) generally does not increase after veraison (Rogiers et al., 2006a). The large drop in xylem hydraulic conductance into the berry, which occurs post-veraison, is correlated with a loss of cell vitality and berry shrivel, and also results in a reduction in calcium import (Tyerman et al., 2004; Rogiers et al., 2006b; Tilbrook and Tyerman, 2009). A varietal survey revealed genotype differences in the occurrence of cell vitality loss and berry shrivel in mature grapes (Fuentes et al., 2010). It is not inconceivable that the reduction in $\mathrm{Ca}^{2+}$ import could contribute to cell vitality, with those grape varieties that maintain longer periods of water and $\mathrm{Ca}^{2+}$ potentially less susceptible to shrivel. The shift away from xylem water delivery during ripening also effectively buffers the fruit against fluctuations in plant water status and water stress events that may affect the plant during ripening (Thomas et al., 2006; Choat et al., 2009). Determining the hydraulic pathways of ionic delivery is vital for understanding patterns of distribution and accumulation and their effects upon fruit development and ripening.

Cation exchange within the xylem plays an important role in $\mathrm{Ca}^{2+}$ delivery; CEC is a measure of the abundance of fixed negative charges in the cell wall, a key determinant of the diffusion pattern of cations through the apoplasm. However, studies that have measured the CEC of the xylem are few. The CEC of cell walls for calcium from different root and shoot tissues of Picea abies has been measured using transmission electron microscopy energy-dispersive microanalysis. Whilst there was a wide variation between root and shoot tissue CEC was observed, the CEC of the secondary cell wall of xylem tracheids was consistently low $(\sim 24 \mathrm{meq} / \mathrm{kg}$ wall material; Fritz, 2007). This suggests that the composition of other zones within the xylem (e.g., pit membranes) and cellular membrane transport mechanisms may also be important for determining $\mathrm{Ca}^{2+}$ transport and buffering fluctuations in xylem sap calcium concentration (Figure 1).

\section{Calcium and Hydraulic Conductivity}

Compartmentation resulting in high hydraulic resistance in the apoplasm occurs in many tissues. Examples of this include; separation of the extracellular space of the outer root from the root endodermis by the Casparian strip (Nawrath et al., 2013), separation of adjacent xylem conduits by pit membranes (Zwieniecki et al., 2001; Plavcova and Hacke, 2011; van Doorn et al., 2011), separation of the leaf xylem from the leaf apoplasm by bundle sheath cells, and separation of external surfaces of the plant and the underlying apoplasm by the cuticle (Nawrath et al., 2013). Changes in the hydraulic resistance $\left(R_{\mathrm{h}}\right)$ of components of the bunch and berry vascular architecture of grapes may account for some of the observed varietal differences in susceptibility to berry shrivel. By studying the $R_{\mathrm{h}}$ of each component the contributions of particular variables to observed changes in xylem flows may be identified (Tyerman et al., 2004; Choat et al., 2009; Mazzeo et al., 2013). These variables may include; physical barriers (i.e., pit membrane porosity and xylem vessel diameter), structural changes (i.e., formation of pectin gels within the xylem), and cellular water permeability (i.e., through changes in temporal and spatial expression of aquaporins; Figure 1). A recent study has demonstrated that hydraulic conductivity of xylem vessels in grape pedicels decreased at veraison and throughout ripening, potentially due to blockages formed by pectin deposition (Knipfer et al., 2015). This effective compartmentation of the apoplasmic space highlights the importance of understanding physical transport barriers as well 


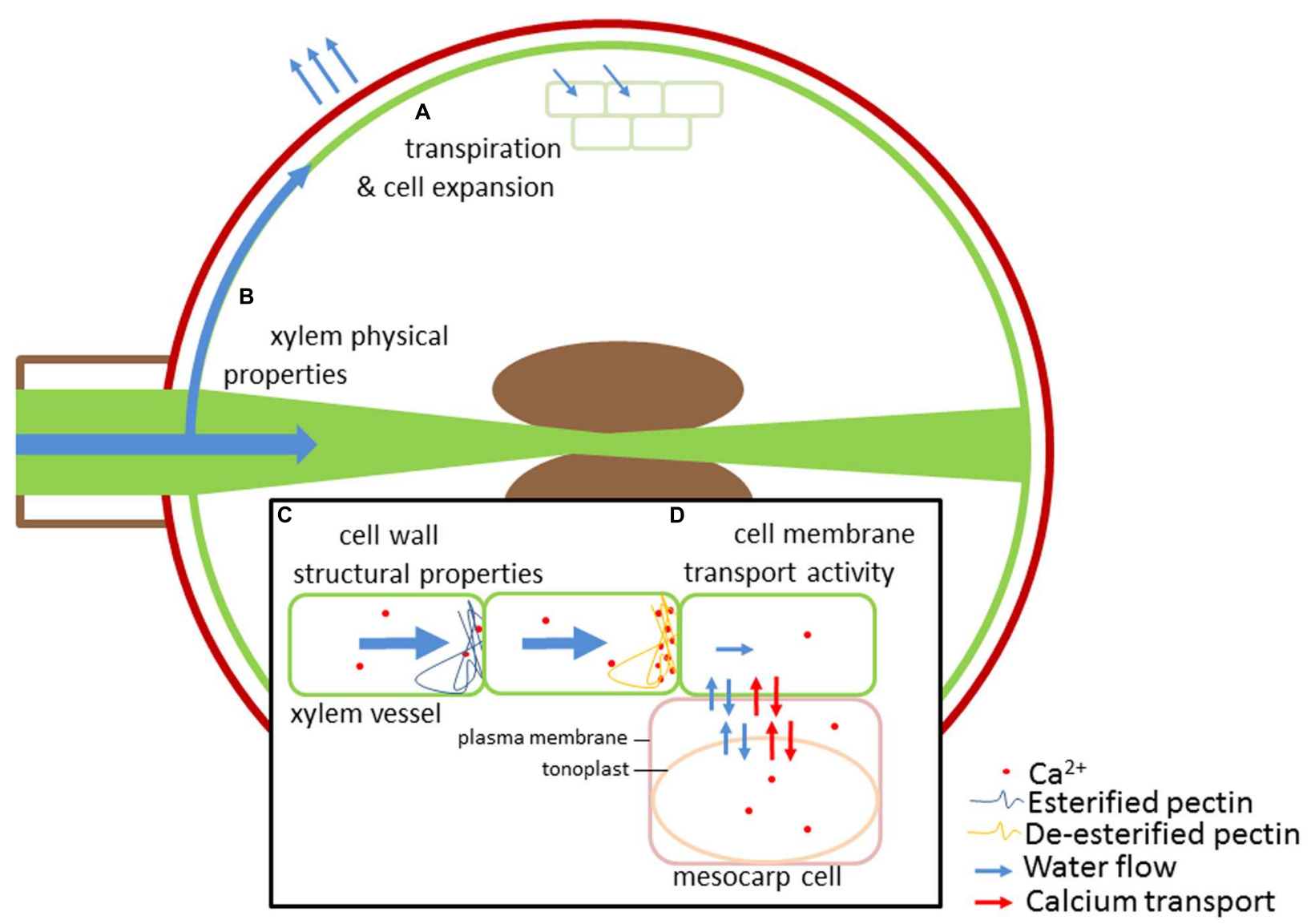

FIGURE 1 | Several major components determine calcium supply and distribution in fruit. Calcium is phloem immobile, accumulating through the xylem. Hydraulic factors, particularly fruit water uptake and loss driven by cell expansion and transpiration largely determine the volume of xylem fluid supplied to the fruit (A). Physical properties of the xylem, including xylem vessel development, vessel diameter and connectivity will influence xylem flow into different tissues of the fruit (B). Structural properties of the cell wall, both in xylem vessels and fruit mesocarp and epidermal tissues, can affect the rate of xylem flow and calcium binding in these compartments $\mathbf{( C )}$. Pectin is a major component of fruit cell walls; de-esterification of pectin enables formation of calcium crosslinked gels affecting pit membrane porosity, xylem flows and calcium distribution. Additionally, tight regulation of cytosolic calcium concentration occurs through a network of membrane transporters on the plasma membrane and tonoplast, including aquaporins, $\mathrm{Ca}^{2+}$-ATPases and CAX ion channels (D). These transport mechanisms can enable accumulation of calcium in particular tissues.

as cellular transport mechanisms for controlling $\mathrm{Ca}^{2+}$ movement and utilization.

A developmental switch to phloem water delivery from predominantly xylem driven delivery reduces the direct hydraulic link of fruit water status to that of the plant (Greenspan et al., 1994). During normal grape development a decrease in mesocarp turgor coincides with the onset of veraison, indicative of phloem solute unloading. Water stress can also cause a drop in fruit mesocarp turgor; however, after veraison, berry mesocarp turgor does not appear to respond to vine water deficit (Thomas et al., 2006). When pre-veraison berries were physically boxed to restrict veraison associated cell expansion, both sugar accumulation and the drop in mesocarp turgor pressure were delayed. When the box was ventilated to allow transpiration, delayed sugar accumulation was not observed and the mesocarp turgor drop was less delayed (Matthews et al., 2009). This suggests that fruit transpiration is required to assist in phloem sugar loading into fruit (by removing excess water;
Lang and Thorpe, 1989), and that ripening related changes in mesocarp cell turgor pressures are linked to both rapid cell expansion and sugar accumulation (Matthews et al., 2009). Calcium is involved in the regulation of cell expansion and elongation during pollen tube tip growth through dynamic pectin binding (Jiang et al., 2005; Rounds et al., 2011), binding signaling proteins and modifying ion channel activity (Konrad et al., 2011). Calcium may also be involved in the changes in cell turgor pressure and cell expansion observed during the progression of fruit ripening. The relative contributions of turgor and cell wall changes to fruit softening are still a major point of discussion. However, it is clear that both factors contribute to the onset and development of ripening processes in fruit through complex interactive pathways and feedback mechanisms.

Fruit water relations and ripening-linked shifts in fruit hydraulic conductance vary between species. Kiwifruit (Actinidia chinensis) maintains positive water fluxes from both the phloem 
and xylem into the fruit throughout development, with each pathway contributing approximately equally to the water balance (Clearwater et al., 2012). However, when grown in high vapor pressure deficit conditions A. chinensis var. chinensis 'Hort16A' exhibits late ripening shrivel, similar to the phenomenon observed in Shiraz grapes. The high surface conductance and transpiration rate observed in Hort16A may cause an imbalance between water delivery to the fruit and transpiration losses (Clearwater et al., 2012). Additionally, kiwifruit does not accumulate sugars until late in the ripening phase; this difference may explain its ability to maintain xylem flow from the plant into the fruit throughout development. A study of kiwifruit xylem hydraulic resistance $\left(R_{\mathrm{h}}\right)$ throughout development using pressure chamber and flow meter techniques showed a general increase in $R_{\mathrm{h}}$ during the second half of fruit development, consistent with previous reports in grapevine and kiwifruit (Tyerman et al., 2004; Choat et al., 2009; Mazzeo et al., 2013). However, the increase in $R_{\mathrm{h}}$ began prior to ripening, indicating that decreasing xylem inflows in kiwifruit may be attributable to increasing xylem hydraulic resistance (Mazzeo et al., 2013). This contrasts to observations in grape; xylem flow rates into the berry drop around veraison whereas increases in $R_{\mathrm{h}}$ are observed after veraison (Tyerman et al., 2004; Choat et al., 2009). The parallel use of pressure chamber and flow meter techniques (Mazzeo et al., 2013), and an evaporative flux method (Clearwater et al., 2012), showed differences in the magnitude of resistance measured depending on the methodology employed. The flow meter technique may also underestimate xylem resistance, with the calculations used for estimation of berry hydraulic isolation and the potential for xylem backflow being questioned (Mazzeo et al., 2013). Despite difficulties in accurately and consistently measuring hydraulic resistance, it is highly likely that differences in xylem sap ionic composition and xylem physical properties will contribute to fruit water relations.

\section{Interactions between Membrane Transport and Fruit Calcium Physiology}

The influence of transport proteins on the long distance transport of $\mathrm{Ca}^{2+}$ has been reviewed previously (Gilliham et al., 2011b), and varies at both the inter- and intra-species level (White, 2001; Cholewa and Peterson, 2004; Conn et al., 2012); in grapevine the choice of rootstock has also been shown to influence shoot accumulation of calcium (Kidman et al., 2014). The presence of a suberized endodermis limits root apoplasmic flow making symplastic transport a necessity, and the dominant pathway of root xylem loading at low transpiration. Regulation of $\mathrm{Ca}^{2+}$ transport across the plasma membrane and organellar membranes is tightly controlled by the expression pattern, interaction and post-transcriptional control of many $\mathrm{Ca}^{2+}$ transporters (Kudla et al., 2010; Figure 1). For example, the differentially regulated expression of a number of membrane ion transporters is responsible for cell-specific calcium accumulation patterns in plants (Conn and Gilliham, 2010; Conn et al., 2011; Gilliham et al., 2011a). The use of both cell-specific ion and transcript profiling and of genomic and transcriptional natural variation amongst varieties of certain plant species has been useful in the identification of these transporters (Conn et al., 2012). In Arabidopsis, knockout of the vacuolar $\mathrm{Ca}^{2+} / \mathrm{H}^{+}$antiporters AtCAX1 and AtCAX3 resulted in lower mesophyll $\mathrm{Ca}^{2+}$ sequestration and higher apoplasmic $\mathrm{Ca}^{2+}$, with physiological impacts ranging from reduced stomatal aperture, stomatal conductance and $\mathrm{CO}_{2}$ assimilation to reduced cell wall extensibility and leaf growth rate (Conn et al., 2011). Constitutive expression of sCAX1, the Arabidopsis vacuolar calcium transporter with its autoinhibitory region removed, in transgenic tomatoes, increased fruit calcium concentration and vacuolar $\mathrm{Ca}^{2+}$ transport (Park et al., 2005). Interestingly, susceptibility to blossom end rot was also increased in these transgenic lines (Park et al., 2005; de Freitas et al., 2011). The constitutive expression of the sCAX1 increased vacuolar calcium accumulation, depleting pools of apoplasmic and cytosolic $\mathrm{Ca}^{2+}$, causing increased membrane leakage and blossom end rot (de Freitas et al., 2011). Although some calcium transport mechanisms have been investigated in fruit, calcium signaling in fruit has not, so the broader impact of calcium nutrition, transport and signaling pathways on fruit development and ripening is still largely unknown.

Plants tightly control cellular $\mathrm{Ca}^{2+}$ transport in order to keep $\left[\mathrm{Ca}^{2+}\right]_{\text {cyt }}$ within the range $(\sim 0.1-10 \mu \mathrm{M})$ required for signal transduction (Evans et al., 1991; White, 2000; Dodd et al., 2010). Regulated fluctuations in $\left[\mathrm{Ca}^{2+}\right]_{\mathrm{cyt}}$ form the "calcium signature" which is a major determining factor in the specificity of downstream transcriptional and physiological responses (McAinsh and Pittman, 2009; Dodd et al., 2010; Kudla et al., 2010). Different environmental stimuli create specific calcium signatures in particular cell-types (Kiegle et al., 2000; Dodd et al., 2010; Marti et al., 2013). The channels responsible for regulating these calcium transients are still largely unknown, with progress having been reviewed by Swarbreck et al. (2013). Electrically induced calcium transients with different amplitudes and frequencies were shown to induce distinct patterns of gene expression (Whalley and Knight, 2013), indicating that environmental stimuli can translate into specific expression profile changes in calcium signaling components. There is considerable evidence indicating that $\mathrm{Ca}^{2+}$ signaling transients also occur in compartments other than the cytosol, e.g., the nucleus, chloroplasts and the apoplasm (Johnson et al., 1995, 2006; Tang et al., 2007; McAinsh and Pittman, 2009). However, these mechanisms are not nearly as well characterized as the cytosolic pathways. Furthermore, $\mathrm{Ca}^{2+}$ transient signaling in fruit specific cell types has not been studied. Generic models for how transients are developed in plant tissue and which transporters are involved in their generation are illustrated in reviews such as Kudla et al. (2010) and de Freitas and Mitcham (2012), these are also useful in the context of understanding the nutritional fluxes of $\mathrm{Ca}^{2+}$ and how these may affect compartmentation of $\mathrm{Ca}^{2+}$ apoplasmically, in the cytoplasm and intracellularly.

Increases in apoplasmic calcium can result in increases in $\left[\mathrm{Ca}^{2+}\right]_{\mathrm{cyt}}$; this has been used to control the duration and 
amplitude of $\left[\mathrm{Ca}^{2+}\right]_{\text {cyt }}$ oscillations in stomatal guard cells to affect guard cell closure (Allen et al., 2001; Webb et al., 2001). In planta manipulation of apoplastic calcium $\left(\left[\mathrm{Ca}^{2+}\right]_{\text {apo }}\right)$ can reduce $\mathrm{CO}_{2}$ assimilation and transpiration rate, through reducing stomatal aperture (Conn et al., 2011). Some components of an extracellular calcium-sensing pathway have been described; where a plastid localized calcium sensor protein (CAS) mediates stomatal closure in response to changes in extracellular calcium (Han et al., 2003; Wang et al., 2012). Antisense cas lines showed reduced water use efficiency and photosynthetic electron transport rate, due to reduced control of stomatal aperture and transcription of electron transport components (Wang et al., 2014), demonstrating the importance of the extracellular calcium signaling pathways in optimizing photosynthesis and water use. The supply of $\mathrm{Ca}^{2+}$ to fruit is dependent upon transpirational water flow and storage rate (i.e., $\mathrm{Ca}^{2+}$ transport into the vacuole via CAX transporters; Conn et al., 2011), therefore $\left[\mathrm{Ca}^{2+}\right]_{\text {apo }}$ in both leaves and fruit are likely to have an impact on $\mathrm{Ca}^{2+}$ supply; furthermore, high $\left[\mathrm{Ca}^{2+}\right]_{\text {apo }}$ in fruit will directly regulate $\left[\mathrm{Ca}^{2+}\right]_{\text {cyt }}$, cell wall properties, gene expression and water relations of the fruit, but the impact that this has on fruit quality outcomes at harvest and during storage is totally unexplored.

Characterization of changes in apoplasmic and vacuolar solute composition that supply grapes supports the notion of a switch from symplasmic to apoplasmic unloading of phloem solutes during late ripening. The table grape variety Concord maintains high apoplasmic $\mathrm{pH}$ (relative to vacuolar $\mathrm{pH}$ ) late into ripening, whereas, in the shrivel susceptible variety Merlot the $\mathrm{pH}$ difference between these compartments is reduced to zero during late ripening, indicating a loss of membrane selectivity in this variety (Keller and Shrestha, 2014). This is supported by recent measurements of electrical impedance in Shiraz berries (Caravia et al., 2015). The switch to apoplasmic phloem unloading enables accumulation of high sugar levels in ripening fruit but also modifies the conditions of the apoplast with potential impacts on cell wall modification and calcium binding. Merlot demonstrates a dramatic jump in apoplasmic glucose and fructose concentrations during the transition from red to ripe berries (Keller and Shrestha, 2014). The accumulation of sugars in the apoplasm activates cell wall localized invertases and hexose/proton transport pathways in berries (Hayes et al., 2007). The loss of cell turgor, vitality, and membrane integrity in the locular tissues during ripening may be related to apoplasmic unloading and the ongoing accumulation of solutes from the adjacent central vasculature (Tyerman et al., 2004; Krasnow et al., 2008). However, the onset of berry death normally occurs after the transition to apoplasmic unloading. Additionally, cell membrane capacitance in the berry is maintained through the cell death phase, indicating intact membranes (Caravia et al., 2015). This suggests that rather than 'cell death', the loss of cell vitality often observed may actually represent a loss of membrane selectivity allowing distribution of some solutes (e.g., sugars, ions, and perhaps the cell vitality stain fluorescein diacetate) into the apoplasm. The effect of solute accumulation in the apoplasm and associated changes in cell turgor on fruit water relations requires further investigation.

\section{CALCIUM-CELL WALL INTERACTIONS DURING FRUIT DEVELOPMENT}

The cell wall is composed of a diverse array of complex polysaccharides. In dicots, the primary cell wall consists of cellulose microfibrils bound in a matrix of pectins and hemicelluloses. The Cellulose is extruded through the plasma membrane by cellulose synthase complexes, whereas pectins and hemicelluloses are synthesized within the Golgi apparatus, and are transported to the cell surface where further synthesis and modification may take place (Gendre et al., 2013). The matrix polysaccharides are very diverse in their composition, with a variety of sugar residues, linkages and side chains present; their synthesis and modification is therefore accomplished by a large number of genes (Burton et al., 2010). The cell wall is a dynamic structure that responds to both developmental and environmental stimuli by structural remodeling; environmental perturbations include pathogen attack, light, and touch (Hoson, 1998; Seifert and Blaukopf, 2010). Cell wall modifying enzymes activated at different stages of development, and under certain conditions (e.g., heat, $\mathrm{pH}$ changes in the apoplasm), are responsible for modification and degradation of cell wall polysaccharides (Grignon and Sentenac, 1991; Brummell, 2006). The chemical changes that occur in fruit cell walls during development include; modification of pectin side chains, depolymerisation of pectins, and degradation of xyloglucan (a hemicellulose), and the activity of non-catalytic proteins such as expansions and AGPs. Together with other ripening related processes (such as the accumulation of solutes) this leads to a number of physical and textural changes in fruit that can help us to classify different types of fruit by their ripening mechanisms. Physical changes in fruit cell walls are associated with ongoing modification and solubilisation of pectins; calciumpectin cross-links are a key factor in determining pectin physical properties.

\section{General Calcium and Pectin Interactions}

Pectins are a complex family of polysaccharides that are structurally related by the occurrence of $(1,4)$ - $\alpha$-linked galacturonan in the backbone, commonly as homogalacturonan, or as the rhamnose/galacturonan disaccharide repeat rhamnogalacturonan-I (Mohnen, 2008). The galacturonan residues of the backbone may be methyl-esterified or acetylated; homogalacturonan is secreted into the cell wall in an esterified form (Willats et al., 2001). A wide variety of linear and branched side chains are also observed, forming the pectin structural classes rhamnogalacturonan-II, xylogalacturonan, and apiogalacturonan. Rhamnogalacturonan-II is the most complex pectin, it can include up to 12 different sugar residues and more than 20 different linkage types. These have been reviewed previously (Vorwerk et al., 2004; Mohnen, 2008; Burton et al., 2010). The structural complexity of pectin, driven by the expression of a range of pectin synthesizing and modifying enzymes throughout development, implicates pectin in an array of potential interactions and functional roles.

The prevalence of ionic and ester bonds between adjacent pectins play an important role in the physical properties 
of fruit cell walls. These bond interactions influence the solubility of pectins. Suitable ions for cross-linking adjacent pectins include calcium-forming junctions between de-esterified homogalacturonans and boron forming di-ester bonds between rhamnogalacturonan II units. Associations between adjacent homogalacturonans ionically linked by calcium ions have been characterized as forming an "egg-box" structure. Although this structure has been demonstrated in pectin extracts (Tibbits et al., 1998), the diversity of side chains and modifications within the pectic polysaccharides, as well as the complexity of other cell wall components makes such interactions difficult to characterize in planta. The importance of pectin structure for determining the hydraulic and elastic properties of pectin gels has been examined mostly in vitro; understanding the complexity of these cell wall interactions in planta requires further research.

The majority of pectins occur in the middle lamella (outermost part of the extracellular matrix; where cell junctions occur), with smaller amounts observed in the primary cell wall (Lee et al., 2011). Micro-domain localization of calcium in particular extracellular domains is hypothesized to affect cell wall loosening and cell separation (Figure 2). This may be particularly relevant at three way cell junctions where turgor pressure is driving the separation of cells and the formation of large intra-cellular spaces (Willats et al., 2001). It has been suggested that the major physical effects of pectin modification will therefore be in cell-cell adhesion rather than strength of the primary cell wall (Ferguson, 1984). However, species and tissue differences in patterns of pectin deposition and modification (through controlled expression of an array of cell wall modifying enzymes) indicate that the situation may be much more complex.

Cell wall acidification promotes cell growth and expansion by displacing pectin-bound calcium through protonation of pectin carboxyl groups. The $\mathrm{pH}$ of the apoplasm may be affected by the $\mathrm{pH}$ of the xylem sap when water delivery is high, depending on the buffering capacity of the xylem solutes. Control of apoplasm pH occurs through the activity of the plasmamembrane localized $\mathrm{H}^{+}$-ATPase and is buffered by the CEC of the apoplasm. When exposed to high concentrations of $\mathrm{NaCl}$

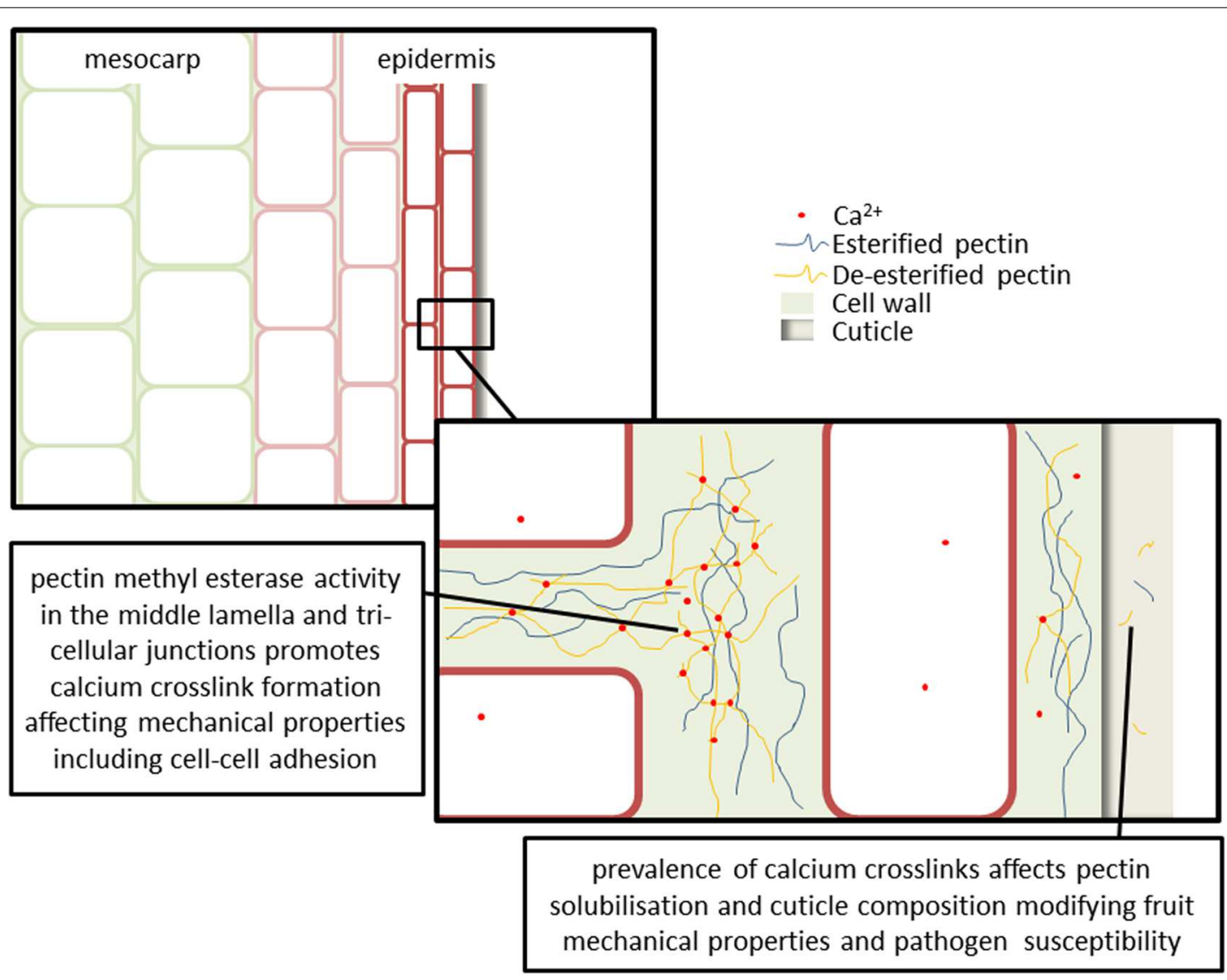

FIGURE 2 | Cell wall changes and calcium-pectin crosslink formation affects fruit mechanical properties, water relations and pathogen susceptibility. Upregulation of cell wall modifying and hydraulic regulatory genes (e.g., pectin methyl esterases, polygalacturonases, and aquaporins) occurs in the mesocarp at veraison. The majority of pectins occur in the middle lamella, with smaller amounts observed in the primary cell wall. Localization of calcium in particular extracellular domains is hypothesized to affect cell wall loosening and cell separation. This may be particularly relevant at three way cell junctions where turgor pressure is driving the separation of cells and the formation of large intra-cellular spaces. Cuticle composition is an important variable in determining both fruit physical properties and transpiration water losses throughout berry development. Processes affecting polysaccharide solubilisation and movement into the cuticle, such as pectin de-esterification and calcium crosslinking, and production of oligogalacturonides will modify fruit mechanical properties and pathogen susceptibility. 
in the growth media a decrease in leaf growth rate of a saltsensitive maize cultivar is correlated with a reduction in $\mathrm{H}^{+}$ATPase activity, resulting in increased apoplasmic $\mathrm{pH}$ whilst a tolerant hybrid cultivar showed none of these effects (Pitann et al., 2009). This finding is contrasted by work measuring ion fluxes in bean leaf, which showed $\mathrm{H}^{+}$efflux from the mesophyll upon addition of $\mathrm{NaCl}$ directly to the mesophyll (Shabala, 2000), although this may be in part related to the displacement of $\mathrm{H}^{+}$from the cell wall by $\mathrm{Na}^{+}$. Amelioration of the effects of salinity on growth by high calcium has been observed; this may result from interactive effects with plasma membrane transport proteins (such as $\mathrm{H}^{+}$/cation exchangers), or through a reduction in the rate of $\mathrm{Ca}^{2+}$ displacement from pectin cross links by $\mathrm{Na}^{+}$ and $\mathrm{H}^{+}$ions (Shabala, 2000). Additionally, cell wall localized expansions show optimal activity at low $\mathrm{pH}$. They are believed to act by reducing hydrogen bonding between primary cell wall components, allowing slippage between adjacent polysaccharides and hence cell wall expansion (Sampedro and Cosgrove, 2005; Dal Santo et al., 2013). Thus, changes in apoplasmic $\mathrm{pH}$ can have significant effects on the dynamics and composition of the cell wall.

\section{Calcium, Pectin, and Fruit Softening}

Fruit softening is often attributed to changes in the composition of the cell wall, and particularly to the impact of pectin deesterification and calcium crosslink formation on cell wall physical properties including strength and elasticity, cell wall loosening and swelling (Figure 2). Changes in $\left[\mathrm{Ca}^{2+}\right]_{\text {apo }}$ and the secretion and modification of pectins are important for the physical development of fruit. Some species (e.g., strawberry and plum) exhibit cell wall swelling during ripening which results in a soft textured fruit, whereas other species (e.g., watermelon and apple) do not exhibit swelling and maintain crisp textured fruit (Redgwell et al., 1997).

Throughout fruit ripening, pectin de-esterification occurs by the action of PMEs. This exposes the carboxyl residues that can be cross-linked by calcium. The level of PME activity and $\mathrm{Ca}^{2+}$ availability within the apoplasm has a direct impact on cell wall strength and expansion (Conn et al., 2011). Studies in grapes suggest that PME expression begins before veraison and continues throughout ripening (Barnavon et al., 2001; Schlosser et al., 2008; Figure 2). Mesocarp and skin tissues exhibit different patterns of PME expression in grapes (Nunan et al., 1998; Schlosser et al., 2008; Lacampagne et al., 2010). During the initiation of ripening a raft of cell wall modifying and hydraulic regulatory genes in grape (including expansions EXP3 and EXPL, pectate lyase, a pectin methyl esterase, and aquaporin PIP2;1) are upregulated (Schlosser et al., 2008). This occurs initially in mesocarp; the delayed activation of these genes in the skin suggests a role for the skin in moderating berry growth during ripening. The degree of pectin de-esterification also varies between varieties (Ortega-Regules et al., 2008).

The expression and activity patterns of cell wall modifying enzymes in grapes change throughout development, as well as varying between varieties. In both Cabernet Sauvignon and Semillon, polygalacturonase activity appears correlated with ABA levels, reaching a maximum at veraison (Deytieux et al.,
2005). Polygalacturonase activity in skin was not detected, however, transcripts of two isoforms showed different expression patterns, with a common feature being greater expression late in development (100 days after anthesis), indicating a variety of roles for the polygalacturonase family, and a concerted role in cell wall disassembly at maturity (Deytieux-Belleau et al., 2008). However, other research has also indicated that transcript expression of polygalacturonases does not necessarily translate to detectable enzyme activity (Nunan et al., 2001). In vitro calcium has an inhibitory effect on polygalacturonase activity; a reduction in calcium concentration and availability following veraison may be linked to a concurrent increase in polygalacturonase activity (Cabanne and Doneche, 2001). In grape skin tissue pectin methylesterase is present throughout ripening with enzyme activity reaching a peak at the beginning of veraison, then decreasing sharply in the subsequent 10 days and increasing steadily thereafter (Deytieux-Belleau et al., 2008). Low levels of polygalacturonase and pectate lyase activity are observed during some stages of ripening; however, hormonal cues may regulate the targeted expression of specific isoforms to drive the depolymerisation of pectin observed during ripening (Nunan et al., 2001).

In addition to the de-esterification of pectins observed in fruit cell walls during ripening, depolymerisation of pectins to shorter sub-units is also an important factor. By using a chelator (e.g., CDTA) followed by size exclusion chromatography to extract and characterize ionically bound pectins, the diversity in timing and degree of depolymerisation that occurs between species can be observed. Some species show almost no change in pectin composition or solubilisation throughout development (e.g., capsicum), whilst others (e.g., tomato) show high degrees of depolymerisation and high levels of chelator soluble pectins (i.e., high levels of calcium bound pectins; Brummell, 2006). This depolymerisation is achieved through the action of polygalacturonases and pectate lyases. Polygalacturonases are absent or detected at very low levels in the fruit of some species which may account for some of the differences in levels of pectin solubilisation. Additionally, it has been demonstrated that reduced expansion activity (normally responsible for loosening of xyloglucan and cellulose networks in the primary cell well during cell expansion) decreases solubilisation of primary cell wall pectins, possibly through reduced access of polygalacturonases to their substrates in this space (Brummell et al., 1999). This finding suggests that it is important to consider more than just transcript levels or enzyme activity when assessing potential for degradation of particular components; calcium availability and activity of other cell wall enzymes may influence substrate accessibility.

The combinatorial effects of pectin modifying enzyme activity, apoplasm $\mathrm{pH}$ and calcium concentration determine various mechanical properties of pectin gels including compressive strength, water holding capacity, porosity, and elasticity (Tibbits et al., 1998; Willats et al., 2001; Ngouemazong et al., 2012). The strength of calcium crosslinks is $\mathrm{pH}$ dependent, with the strongest bonds forming at apoplasmic $\mathrm{pH}$ 6-7. Formation and dissolution of pectin gels by calcium crosslinks is highly dependent on the level of de-esterification (i.e., available carboxyl groups) and free calcium ion concentration (Tibbits et al., 1998). Gel swelling can 
be observed during cell wall dissolution, due to both the osmotic pressure created by free carboxyl groups in the pectin matrix (occurring when ionic strength is low), and the disassociation of calcium cross-linked pectins. This can be expressed as the ratio of free calcium ions to carboxyl groups (i.e., if $\left[\mathrm{Ca}^{2+}\right]$ free: $\mathrm{COO}^{-}<0.05$ significant swelling is likely to occur). As gel dissolution and swelling occurs, the breakdown of calcium crosslinks reduces the stiffness of the gel. Swelling of a gel is generally at maximum around $\mathrm{pH}$, which is also the $\mathrm{pH}$ at which calcium crosslinking and gel shear strength are at a minimum (Tibbits et al., 1998). Reported work with pectin concentrations similar to those observed in plant cell walls (films with $\sim 30 \%$ pectin), demonstrate that pectin hydration status (or degree of swelling) has a linear inverse relationship with tensile strength (Zsivanovits et al., 2004). Additionally, the hydraulic properties and susceptibility to swelling of the pectin matrix are determined by both the pectin composition and the ionic composition of the space (Zsivanovits et al., 2004). Through understanding the pectin ion interaction effects on gel properties in vitro it is likely we will advance our comprehension of fruit ripening processes.

\section{Calcium, Pectin and Pathogens}

Plant and fungal PMEs have different modes of function; plant PMEs generally operate in a blockwise manner, deesterifying multiple homogalacturonan residues along a single chain, whereas fungal PMEs operate in a non-blockwise manner (Willats et al., 2001). Patterning of pectin modification and calcium binding may affect the attachment and rate of pectin cleavage by polygalacturonases (Figure 2). Three botrytis (Botrytis cinerea) isolates exhibited calcium inhibition of polygalacturonase activity. The calcium concentration required to inhibit enzyme activity varied between isolates (Chardonnet et al., 2000). The pathogenicity of these isolates also varied between four apple varieties, indicating that the interaction between the pathogen cell-wall degrading enzymes and the composition of the fruit cell wall is important for determining pathogenicity (Chardonnet et al., 2000). It has been demonstrated that the calcium content of grape skin cell walls is negatively correlated with susceptibility to botrytis enzymatic digestion (Chardonnet and Doneche, 1995). Calcium infiltration reduced the level of pectin degradation by botrytis in grapes (Chardonnet et al., 1997), and reduced the level of decay in apples (Chardonnet et al., 2000). Complex interactions between calcium nutrition and the diversity of pectin profiles seen in different species, varieties, tissues, organs, and developmental points influence susceptibility to fungal pathogens. These studies indicate that calcium treatments may be worthwhile exploring as a management option for some fruit pathogens (Dayod et al., 2010).

Degradation of pectic homogalacturonan backbones generates short chain molecules known as OGAs; these have been implicated in pathogen defense signaling activation. This role is carried out through OGA binding by the wall-associated kinase (WAK) family (Decreux and Messiaen, 2005). It is likely that functional OGAs may be prevalent in fruit, and often affect ripening, as ripening fruit has high pectin content and is attractive to a variety of pathogens. Many factors influence the defense response eliciting capacity and specificity of OGAs, including; calcium availability, length of OGA, degree of methylesterification and degree of acetylation (Decreux and Messiaen, 2005; Vallarino and Osorio, 2012; Figure 2). The extracellular domain of Arabidopsis WAK1 binds OGAs only in the presence of calcium and calcium crosslink forming conditions (Decreux and Messiaen, 2005). Transgenic expression of a fruit-specific PME from cultivated strawberry in wild strawberry (Fragaria vesca) resulted in a modified pattern of OGA esterification in the transgenic fruit. This change was sufficient to constitutively activate defense responses in the transgenic plant, thereby increasing botrytis resistance (Osorio et al., 2008). A variety of evidence suggests that, in addition to WAKs binding specific OGAs during pathogen responses, they also bind cell wall pectins during normal development to regulate cell expansion (e.g., reduction in WAK expression via antisense has been shown to reduce cell size) reviewed in Kohorn and Kohorn (2012). It is apparent that the specificity of calcium-pectin-WAK interactions may facilitate multiple signaling pathways important in pathogen defense activation as well as during the normal developmental control of cell expansion.

\section{The Influence of the Cuticle}

Changes in cuticle composition (e.g., relative abundance of polysaccharides) can affect fruit mechanical properties and transpiration rate. Fruit cuticles are typically thicker (but also more water permeable) than leaf cuticles; the scarcity of stomata on fruit also suggests that cuticle composition is important for fruit water relations (Martin and Rose, 2014). A study modeling the impacts of environmental variables on kiwifruit transpiration revealed both seasonal and diurnal variation in transpiration rates, with skin conductance being the key fruit variable in determining fruit transpiration rates (Montanaro et al., 2012b). A tomato cultivar ('Delayed Fruit Deterioration') with altered cuticle architecture was shown to have low fruit transpiration and increased cell turgor pressure, leading to delayed softening despite undergoing normal ripening related cell wall modifications (Saladie et al., 2007), and application of gibberellins was shown to increase cuticle thickness in tomato (Knoche and Peschel, 2007). In grapes (cv. Riesling), a drop in the transpiration permeability of the cuticle occurs from preveraison to post-veraison (Becker and Knoche, 2011), and this drop is strongly correlated with increased cuticle deposition (Becker and Knoche, 2012). Indeed, recent work has identified both varietal differences and developmental changes in the cuticular conductance of grape berries, possibly attributable to cuticle composition (Keller et al., 2015). The composition of the cuticle changes throughout development in cherry tomato (cv. Cascada); cuticle mass per unit fruit surface area increased rapidly from 10 days after anthesis to reach a maximum 15 days after anthesis (subsequent increases in cuticle thickness were attributed to reduced cuticle density; Dominguez et al., 2008). Interestingly, another study in the same cultivar looking at the cuticle mechanical properties found a shift from elastic to predominantly viscoelastic behavior from 10 to 15 days after anthesis. These changes in the cuticle mechanical properties were correlated with the ratio of cutin:polysaccharide present; high ratios were associated with cell enlargement growth stages, 
and lower ratios (approaching 1:1) were associated with stages where cell expansion is minimal (i.e., early cell division and later ripening phases; Espana et al., 2014). As such, it is hypothesized that polysaccharides in the cuticle contribute elastic properties, and cutin confers viscoelastic properties. It is clear that cuticle composition is an important variable in determining both fruit physical properties and transpiration water losses.

\section{CALCIUM-HORMONE INTERACTIONS DURING FRUIT DEVELOPMENT}

Calcium is a secondary messenger during hormone signaling. Calcium is known to participate in GA, auxin, and ABA signaling to regulate fruitset, initiation of ripening, cell division, cell expansion, and fruit softening (Ferguson, 1984; Saure, 2005; Yu et al., 2006). Additionally, hormonal regulation of cell expansion, cell wall modification, xylem development, and sugar unloading from the phloem can affect calcium distribution within the fruit (Saure, 2005; de Freitas et al., 2014). Although the physiological pathways and interactions of plant hormones and calcium are still being uncovered, many hormone and calcium treatments are already used for horticultural improvement. The role of plant hormones in fruit development and ripening processes has been extensively reviewed (Ruan et al., 2012; McAtee et al., 2013; Osorio et al., 2013; Wang and Ruan, 2013; Kumar et al., 2014; Leng et al., 2014). As both are components of an array of complex signaling pathways, the accumulation and activity of calcium and phytohormones is tightly controlled at the tissue level. Subsequently, perturbed calcium nutrition may create multiple plant hormonal responses that are difficult to characterize. This section will therefore articulate the current knowledge and gaps in our understanding of calcium and hormone interactions in fruit.

\section{Auxin}

Auxin has key roles in fruitset, cell division and cell expansion. These developmental pathways both utilize calcium as a secondary messenger and affect patterns of calcium distribution. Fruitset and early development are triggered by auxin synthesis in the ovules during fertilization, which induces GA synthesis, reviewed in Kumar et al. (2014). GA signaling in the pericarp of Arabidopsis fruit has been demonstrated to activate a pathway degrading the growth inhibiting DELLA proteins (Fuentes et al., 2012; Kumar et al., 2014). The relationship between GA and auxin is complex, with a GA independent pathway for fruitset being demonstrated in tomato (Serrani et al., 2008; McAtee et al., 2013). High levels of GA are commonly associated with rapid cell expansion and this has also been linked to low or reduced calcium concentrations by disrupting calcium transport (Saure, 2005); the mechanism through which this occurs requires further investigation.

Calcium acts as a secondary messenger downstream of auxin through the acid growth pathway. This pathway has been demonstrated in Arabidopsis; auxin efflux from cells is facilitated by PIN-FORMED (PIN) membrane proteins. PIN activity and targeted endocytotic transport of PIN are regulated by PINOID (PID) protein kinase and PP2A phosphatase complex mediated phosphorylation (Fozard et al., 2013). Extracellular auxin (possibly though the binding of $A B P 1$ ) activates plasma membrane calcium transport in wheat embryos, creating $\left[\mathrm{Ca}^{2+}\right]_{c y t}$ transients that activate the plasma membrane localized $\mathrm{H}^{+}$-ATPase to reduce apoplasmic $\mathrm{pH}$. Lower apoplasmic $\mathrm{pH}$ activates $\mathrm{pH}$ sensitive cell wall loosening enzymes (Rober-Kleber et al., 2003; Shishova and Lindberg, 2010; Wang and Ruan, 2013). This proton influx into the cell wall compartment also increases competition with calcium for binding sites on deesterified pectin, resulting in looser cell walls; as such higher levels of calcium can inhibit auxin-activated acid growth (Ferguson, 1984). $\mathrm{H}^{+}$-ATPase transport also activates voltage dependent inward rectifying $\mathrm{K}^{+}$channels, this results in an increase in $\mathrm{K}^{+}$ content, causing osmotically driven movement of water into the cell, increasing cell turgor pressure. This acid growth pathway is responsible for cell elongation and expansion; it has been observed during growth and hormone-stimulated cell expansion of many tissues. Examples of auxin-calcium interactions in fruit growth are given below.

Auxin is also involved in calcium uptake and distribution in fruit. Application of CME (an auxin transport inhibitor) reduced calcium uptake into developing fruit of some tomato cultivars differing in susceptibility to blossom end rot (Brown and Ho, 1993). This reduced calcium uptake may occur through modification of cellular transport activity or perturbed cell expansion (disrupting xylem development). Calcium is also involved in fruit basipetal auxin transport. CME induced reductions in basipetal IAA efflux were only observed in tomato fruit grown under high salinity conditions where calcium uptake was reduced (Brown and Ho, 1993). In kiwifruit, light induction of higher levels of auxin-protecting hydroxycinnamic acids decreased auxin degradation, resulting in increased calcium uptake (Montanaro et al., 2007). These results suggest that tomato susceptibility to blossom end rot may be determined not just by differences in capacity for calcium uptake and distribution, but also by related factors such as auxin transport and metabolism, and rate of cell enlargement (Bangerth, 1976).

\section{Abscisic Acid}

Fruit ripening processes typically involve $\mathrm{ABA}$ and ethylene signaling. Non-climacteric fruit show a greater reliance upon $\mathrm{ABA}$ for initiation of ripening processes and do not demonstrate the same extent of ethylene responsiveness as climacteric fruit. ABA signaling in Arabidopsis acts through a network of calcium binding signal receptors (PYR/PYL/RCAR) and phosphorylation status modifiers including PP2C protein phosphatases ABI1 and ABI2 (Leung et al., 1994; Allen et al., 1999), and an array of CBL (Pandey et al., 2004), CIPK (Kim et al., 2003), and CDPK (Zhu et al., 2007) protein kinases (Fortes et al., 2015). A systems biology approach has been applied to understand the complexity of interactions and crosstalk between these networks (Cramer et al., 2011).

The concentration of ABA in grapes increases dramatically at the beginning of veraison; it is possible that the drop in cell turgor that occurs at this time triggers increases in ABA content (Castellarin et al., 2011). There are varietal differences in the time 
during veraison (measured as \% color change) at which maximal berry ABA is reached; Merlot ( $10 \%$ color change), Cabernet Sauvignon (50\% color change), and Semillon (100\% color change; Deytieux-Belleau et al., 2008). The partitioning of ABA between mesocarp and skin shifts from $100 \%$ in mesocarp prior to veraison, to approximately $40 \%$ in skin by maturity (DeytieuxBelleau et al., 2008). In non-climacteric fruit (e.g., strawberries and grapes) several other factors have been identified as potential ripening signal elements; auxin treatment of unripe fruit delays ripening (Boettcher et al., 2011) whilst reactive oxygen species accumulate in grape berries at the onset of ripening (Pilati et al., 2014). The transduction of these ripening triggers through the calcium signaling network suggests that calcium also plays a role in sugar accumulation and fruit softening and evidence for these functions are examined below.

Higher ABA levels at ripening leads to hexose accumulation through up-regulation of hexose transporters and increased apoplasmic invertase activity (Pan et al., 2005; Deluc et al., 2009; Hayes et al., 2010). ABA activates sugar cell wall bound invertases at the initiation of grape ripening, catalyzing sucrose cleavage, decreasing the apoplasmic sucrose concentration, and thereby allowing for continued phloem unloading of sucrose into the berry apoplasm (Pan et al., 2005). Phloem unloading of sugars becomes crucial for driving expansion, as well as efficiently maintaining the accumulation of sugars in the fruit. $\mathrm{ABA}$ and sugar responsive elements involved in these pathways have been identified, including an ABA and sugar responsive protein (VvMSR1) that forms part of a complex regulating expression of monosaccharide transporter VvHT1 (Cakir et al., 2003). Microarray expression analysis of cells overexpressing an ABA response element binding transcription factor (VvABF2) demonstrate elevated transcript levels of a vacuolar invertase, a hexose transporter, and cell wall modifying genes linked to fruit softening (i.e., polygalactuonase, pectin methyl esterase and rhamnogalacturonase; Nicolas et al., 2014). It has been demonstrated that ABA activates the calcium dependent protein kinase $(\mathrm{ACPK} 1)$ in grape mesocarp through a complex mechanism involving influx of apoplasmic calcium to the cytosol (Yu et al., 2006). ACPK1 in turn activates plasma membrane $\mathrm{H}^{+}$-ATPase in the berry mesocarp, possibly energizing the cell for solute uptake (Yu et al., 2006). A transient decrease in calcium concentration is observed in the apoplasm of Vicia faba leaves following $\mathrm{ABA}$ treatment, providing further evidence for apoplasmic calcium as a transducer of ABA signaling (Felle et al., 2000). The timing of ABA accumulation, metabolic responses and the drop in turgor varies between varieties with differing ripening profiles (Deluc et al., 2009; Castellarin et al., 2011).

\section{Combined Effects of Hormones}

Endogenous hormone levels influence fruit softening by altering expression levels of enzymes that modify cell turgor pressure, apoplasm solute accumulation, and cell wall modification. Application of GA has been shown to increase berry firmness and shelf life in the table grape variety Thompson Seedless (Marzouk and Kassem, 2011). Suppression of a key enzyme involved in tomato ABA biosynthesis (9-cis-epoxycarotenoid dioxygenase) resulted in the transcriptional down regulation of polygalacturonase, pectin methylesterase, expansion, and many other cell wall modifying enzymes (Sun et al., 2012; Osorio et al., 2013). In Cabernet Sauvignon berries treated with sucrose or sucrose and ABA, a drop in berry firmness (as occurs at the onset of ripening in the field) was only observed in the sucrose and ABA treated berries (Gambetta et al., 2010). The combined effect of ABA-activation of sugar invertases and cell wall modifying enzymes in the apoplasm is to simultaneously reduce cell turgor pressure and loosen cell walls (Pan et al., 2005; Gambetta et al., 2010). Auxin and ABA pathways utilize calcium as both a protein binding secondary messenger and in membrane transport mechanisms that modify turgor and solute accumulation to drive cell expansion and ripening.

\section{IMPLICATIONS OF CALCIUM NUTRITION FOR FRUIT DISEASE SUSCEPTIBILITY}

Understanding the role of calcium in fruit development is important for addressing ripening disorders (e.g., berry shrivel in Shiraz grapes), tissue localized calcium deficiencies (e.g., blossom end rot in tomatoes, bitter pit in apples), and pathogen susceptibilities (e.g., botrytis). Improved understanding of the calcium nutritional requirements of plants may also aid in optimizing fruit quality outcomes as both calcium deficiency and toxicity can affect the productivity of horticultural systems, and the post-harvest characteristics of the crop. Calcium deficiency can occur due to an insufficient mobilization of calcium from internal stores or a reduced supply of calcium through the xylem (often a result of low transpiration rates; White and Broadley, 2003). Calcium toxicity can occur due to high concentrations of available calcium in the soil solution; this can result in reduced growth rates and the ectopic deposition of calcium oxalate crystals (White and Broadley, 2003).

An ABA deficient tomato mutant (sitiens; which exhibits botrytis resistance) exhibits a lower degree of epidermal cell wall pectin de-esterification, reduced cuticle thickness, and increased cuticle permeability, when compared to wild type (Asselbergh et al., 2007; Curvers et al., 2010). The consequent reduction in botrytis susceptibility of sitiens may be as a result of: (a) plant detection of defective cuticle, prompting constitutive expression of chitinases and $\beta$-glucosidases into the cell wall, enabling rapid release of fungal elicitors upon infection, and/or (b) a lower level of de-esterification in sitiens cell walls providing a source of more bio-active OGA elicitors upon infection; thereby producing a more rapid and effective response to pathogen attack (Curvers et al., 2010). The level of esterification in OGAs is one of several factors that determine their activity and specificity in triggering plant responses; it has been shown that the level of de-esterification in strawberry OGAs contributes to their capacity to elicit defense responses (Osorio et al., 2008). Although the exact mechanism of botrytis resistance in sitiens is unknown, it is clear that the interaction between epidermal cell wall derived pectins and the cuticle, either as defense signaling OGAs or as structural components, is important. In addition to the processes controlling deposition of cutin into the cuticle, processes affecting polysaccharide solubilisation and 
movement into the cuticle, such as pectin de-esterification and calcium crosslinking, will modify fruit mechanical properties and pathogen susceptibility.

Blossom end rot in tomatoes is often cited as being a result of calcium deficiency. Tomatoes grown in low calcium nutrient solution show an increase in the incidence of blossom end rot (Coolong et al., 2014). Pericarp elasticity increased with calcium levels in the growth solution (Coolong et al., 2014). GA treatment of tomatoes leads to increased occurrence of blossom end rot while treatment with GA biosynthesis inhibitor prohexadione-calcium eliminated blossom end rot (de Freitas et al., 2012). GA treated tomatoes showed increased expression of CAX and Ca-ATPase genes and reduced apoplasmic $\left[\mathrm{Ca}^{2+}\right]$, whereas GA inhibitor treated fruit showed higher pericarp total calcium levels and an increased number of functional fruit xylem vessels (de Freitas et al., 2012). GA-induced gene expression for CAX and putative endoplasmic reticulum localized CaATPase results in depletion of the apoplasmic calcium pool, possibly below the critical concentration required for pectincalcium crosslinks in the cell wall to maintain membrane stability and moderate cell expansion. Similarly, constitutive expression of an Arabidopsis CAX gene with its autoinhibitory region removed (sCAX1) in tomatoes led to increased calcium accumulation in the fruit pericarp, but lower calcium levels in apoplasm and cytosol compartments (de Freitas et al., 2011). The sCAX1 line showed leakier plasma membranes, with $100 \%$ of fruit demonstrating blossom end rot by 15 days after pollination (de Freitas et al., 2011), highlighting the need for targeted approaches to address localized calcium deficiencies. In addition to the localized decrease in calcium concentration, rapidly expanding tissue (such as the blossom end of tomatoes) may further impede normal fruit calcium distribution due to cellular intrusions causing obstruction or breakage of xylem vessels (Drazeta et al., 2004; de Freitas et al., 2012). Apogee-treated fruit showed increased numbers of functional xylem vessels; the impact of GA on xylem differentiation and development modifies normal pathways for calcium distribution (Saure, 2005). Additionally, GA triggers increased cuticle deposition (Knoche and Peschel, 2007), potentially modifying fruit water relations and calcium uptake. All of these factors provide possible linkages between GA responses and changes in calcium localization leading to blossom end rot.

Other examples of complications arising from sub-optimal calcium nutrition occur in apples and melons. Calcium accumulation in apples is also reduced by progressive breakdown of xylem connectivity as the result of growth related damage, potentially increasing occurrence of bitter pit disorder (Drazeta et al., 2004). In contrast, dye studies in post-veraison grapes indicate that the xylem not only remains relatively intact, but also continues to develop and mature (Chatelet et al., 2008). Application of exogenous calcium has also been proposed as a way to increase apple sugar content and post-harvest shelf life. However, the relationship between calcium and sugar accumulation is complex and many factors appear to affect the effectiveness of this strategy including soil calcium availability, timing of spray/application, apple variety, tree calcium status and in planta interactions with other ions (e.g., boron; Lu et al., 2013). Levels of apple tree shading also have a complex effect, with conflicting reports as to whether apple calcium uptake is increased or decreased with shading (Chen et al., 1997; de Freitas et al., 2013). Melons suffer from a water-soaking condition that has been linked to apoplasmic calcium deficiency where it has been hypothesized that depletion of apoplasmic calcium supply can lead to insufficient pectin crosslinks in the middle lamella of the mesocarp, resulting in water-soaked tissue (Madrid et al., 2004; Nishizawa et al., 2004).

\section{FUTURE PERSPECTIVES}

Whilst advances in the understanding of water relations in the fruit vasculature are being made, interactions between water and specific extracellular domains are still largely uncharacterised. This review has discussed much of the existing literature that explores the interplay between cell wall composition, calcium binding, and water movement through plants. The observed diversity of ripening patterns demonstrates that, even within a species, inferences from these studies should be made with caution when looking at different species, varieties, or conditions.

\footnotetext{
Target areas for further research

How do calcium-pectin interactions affect water movement through fruit xylem vasculature? Are there critical 'control points' in the apoplasm that contribute to fruit water or nutrient deficiencies?

How does the developmental switch from phloem to xylem unloading of solutes affect apoplastic calcium levels, cell wall properties and membrane integrity?

How can our knowledge of calcium delivery, calcium-pectin binding conditions, and calcium signaling pathways during ripening be utilized to address calcium deficiency disorders and improve pathogen resistance?
}

The relative contributions of xylem and phloem to fruit water influx (or loss) are still a subject of contention. Studies of phloem flows and sap composition are notoriously difficult due to the fine and fragile nature of the compartment. Structural changes, the influence of ionic interactions, and osmotic effects within the xylem also make it a complex and dynamic compartment. It is hoped that a more holistic approach which incorporates not only measures of bulk tissue water balance and molecular mechanisms, but also knowledge of osmotic effects, changes in calcium distribution, pectin gels, and diffusion barriers, will help understand some of the idiosyncrasies of fruit water relations during ripening.

Further studies of calcium distribution in the cell wall and xylem vessels would increase our comprehension of the interactions between calcium nutrition, cell wall processes, and berry water relations. Techniques utilizing fluorescent and luminescent chemical or genetic indicators (e.g., Fluo4, aequorin, CaR-GECO1 and pHlourin) could be used for quantifying calcium and $\mathrm{pH}$ differences (and treatment responses) across different fruit cell types. These techniques have already been applied in other plant tissues (e.g., pollen 
tubes) to characterize the role of transport and signaling pathway components (e.g., CDPKs; Michard et al., 2008). Application of microscopy techniques for mapping ion concentrations and histochemical localization of cell wall component modifications throughout fruit ripening would also be beneficial. Particularly, combining calcium localization at a sub-cellular level using $\mathrm{X}$-ray microanalysis, or equivalent techniques, with localization of esterified and de-esterified pectins using antibody probes could describe patterns of calcium movement and accumulation in fruit as well as identifying the location of calcium-pectin binding and gel formation (Conn et al., 2011). These results could be correlated with physical properties of fruit (e.g., fruit firmness, elasticity, and skin strength) determined by standard and high throughput methodologies on materials testing devices. This type of approach would bridge the gap between understanding of molecular mechanisms of ion transport and cell wall modification, and observations of fruit physiology impacts on harvest and post-harvest traits.

As the molecular mechanisms of calcium and water transport across cellular membranes are elucidated, and more RNA expression studies in particular fruit and cell types become available (e.g., Fasoli et al., 2012; Sato et al., 2012; Karlova et al., 2014; Palumbo et al., 2014), understanding of the influence of molecular mechanisms on pathways of water and calcium distribution will be improved. Additionally, these studies would help to describe the expression of genes involved in the developmental and stress-induced changes to cell wall composition and modification. This includes elucidation of transcription factor controls, pathogen responses through OGA release from the cell wall and binding by WAKs. The transduction of hormonal signals through calcium dependent kinase networks is also gaining more attention; translation of the functions of these networks in fruit will be an important future development.

\section{REFERENCES}

Allen, G. J., Chu, S. P., Harrington, C. L., Schumacher, K., Hoffman, T., Tang, Y. Y., et al. (2001). A defined range of guard cell calcium oscillation parameters encodes stomatal movements. Nature 411, 1053-1057. doi: 10.1038/ 35082575

Allen, G. J., Kuchitsu, K., Chu, S. P., Murata, Y., and Schroeder, J. I. (1999). Arabidopsis abi1-1 and abi2-1 phosphatase mutations reduce abscisic acidinduced cytoplasmic calcium rises in guard cells. Plant Cell 11, 1785-1798. doi: $10.2307 / 3871054$

Alleva, K., Niemietz, C. M., Maurel, C., Parisi, M., Tyerman, S. D., and Amodeo, G. (2006). Plasma membrane of Beta vulgaris storage root shows high water channel activity regulated by cytoplasmic $\mathrm{pH}$ and a dual range of calcium concentrations. J. Exp. Bot. 57, 609-621. doi: 10.1093/jxb/erj046

Asselbergh, B., Curvers, K., Franca, S. C., Audenaert, K., Vuylsteke, M., Van Breusegem, F., et al. (2007). Resistance to Botrytis cinerea in sitiens, an abscisic acid-deficient tomato mutant, involves timely production of hydrogen peroxide and cell wall modifications in the epidermis. Plant Physiol. 144, 1863-1877. doi: 10.1104/pp.107.099226

Bangerth, F. (1976). A role for auxin and auxin transport inhibitors on the Ca content of artificially induced parthenocarpic fruits. Physiol. Plant. 37,191-194. doi: 10.1111/j.1399-3054.1976.tb03956.x

Barnavon, L., Doco, T., Terrier, N., Ageorges, A., Romieu, C., and Pellerin, P. (2001). Involvement of pectin methyl-esterase during the ripening of grape berries: partial cDNA isolation, transcript expression and changes in the
With this data in hand, a more informed comprehension of the relationships between different components of these pathways will be established.

Although many of the individual roles of calcium in fruit are now being demonstrated, the effect of changes in calcium nutrition on fruit development, susceptibility to pathogens and calcium-related disorders is still lacking. The importance of calcium nutrition in determining susceptibility to major horticultural disorders has been established. However, the amelioration of these disorders and improvement in pathogen resistance through calcium fertilization does not deliver reliable results. Further studies that modify calcium nutrition without affecting other ionic interactions may improve the understanding of optimum plant calcium nutrition and enable better strategies for avoiding fruit physiological disorders and improving fruit physical traits at harvest.

\section{AUTHOR CONTRIBUTIONS}

$\mathrm{BH}$ wrote the majority of the manuscript with input from MG. MG, ST, and RB supervised BH's Ph.D. from where this review originated. All authors edited and commented on the manuscript.

\section{ACKNOWLEDGMENTS}

We would like to thank the University of Adelaide for supporting the Ph.D. research by $\mathrm{BH}$, which produced this review. This research was conducted in the Australian Research Council funded Centre of Excellence in Plant Energy Biology (CE140100008) and Centre of Excellence in Plant Cell Wells (CE110001007); MG is supported by an ARC Future Fellowship (FT130100709).

degree of methyl-esterification of cell wall pectins. Phytochemistry 58, 693-701. doi: 10.1016/S0031-9422(01)00274-6

Becker, T., and Knoche, M. (2011). Water movement through the surfaces of the grape berry and its stem. Am. J. Enol. Vitic. 62, 340-350. doi: 10.5344/ajev.2011.10056

Becker, T., and Knoche, M. (2012). Deposition, strain, and microcracking of the cuticle in developing 'Riesling' grape berries. Vitis 51, 1-6.

Boettcher, C., Harvey, K., Forde, C. G., Boss, P. K., and Davies, C. (2011). Auxin treatment of pre-veraison grape (Vitis vinifera L.) berries both delays ripening and increases the synchronicity of sugar accumulation. Aust. J. Grape Wine Res. 17, 1-8. doi: 10.1111/j.1755-0238.2010.00110.x

Brown, M. M., and Ho, L. C. (1993). Factors affecting calcium-transport and basipetal IAA movement in tomato fruit in relation to blossom-end rot. J. Exp. Bot. 44, 1111-1117. doi: 10.1093/jxb/44.7.1111

Brummell, D. A. (2006). Cell wall disassembly in ripening fruit. Funct. Plant Biol. 33, 103-119. doi: 10.1071/FP05234

Brummell, D. A., Harpster, M. H., Civello, P. M., Palys, J. M., Bennett, A. B., and Dunsmuir, P. (1999). Modification of expansin protein abundance in tomato fruit alters softening and cell wall polymer metabolism during ripening. Plant Cell 11, 2203-2216. doi: 10.1105/tpc.11.11.2203

Burton, R. A., Gidley, M. J., and Fincher, G. B. (2010). Heterogeneity in the chemistry, structure and function of plant cell walls. Nat. Chem. Biol. 6, 724-732. doi: 10.1038/nchembio.439

Cabanne, C., and Doneche, B. (2001). Changes in polygalacturonase activity and calcium content during ripening of grape berries. Am. J. Enol. Vitic. 52, 331-335. 
Cakir, B., Agasse, A., Gaillard, C., Saumonneau, A., Delrot, S., and Atanassova, R. (2003). A grape ASR protein involved in sugar and abscisic acid signaling. Plant Cell 15, 2165-2180. doi: 10.1105/tpc.013854

Caravia, L., Collins, C., and Tyerman, S. D. (2015). Electrical impedance of Shiraz berries correlates with decreasing cell vitality during ripening. Aust. J. Grape Wine Res. 21, 430-438. doi: 10.1111/ajgw.12157

Castellarin, S. D., Gambetta, G. A., Wada, H., Shackel, K. A., and Matthews, M. A. (2011). Fruit ripening in Vitis vinifera: spatiotemporal relationships among turgor, sugar accumulation, and anthocyanin biosynthesis. J. Exp. Bot. 62, 4345-4354. doi: 10.1093/jxb/err150

Chardonnet, C., and Doneche, B. (1995). Relation between calcium content and resistance to enzymatic digestion of the skin during grape ripening. Vitis 34, 95-98.

Chardonnet, C., Lhyvernay, A., and Doneche, B. (1997). Effect of calcium treatment prior to Botrytis cinerea infection on the changes in pectic composition of grape berry. Physiol. Mol. Plant Pathol. 50, 213-218. doi: 10.1006/pmpp.1996.0075

Chardonnet, C. O., Sams, C. E., Trigiano, R. N., and Conway, W. S. (2000). Variability of three isolates of Botrytis cinerea affects the inhibitory effects of calcium on this fungus. Phytopathology 90, 769-774. doi: 10.1094/PHYTO.2000.90.7.769

Chatelet, D. S., Rost, T. L., Shackel, K. A., and Matthews, M. A. (2008). The peripheral xylem of grapevine (Vitis vinifera). 1. Structural integrity in postveraison berries. J. Exp. Bot. 59, 1987-1996. doi: 10.1093/jxb/ern060

Chen, K., Hu, G. Q., and Lenz, F. (1997). Training and shading effects on vegetative and reproductive growth and fruit quality of apple. Gartenbauwissenschaf 62, 207-213.

Choat, B., Gambetta, G. A., Shackel, K. A., and Matthews, M. A. (2009). Vascular function in grape berries across development and its relevance to apparent hydraulic isolation. Plant Physiol. 151, 1677-1687. doi: 10.1104/pp.109.143172

Cholewa, E., and Peterson, C. A. (2004). Evidence for symplastic involvement in the radial movement of calcium in onion roots. Plant Physiol. 134, 1793-1802. doi: $10.1104 /$ pp.103.035287

Clearwater, M. J., Luo, Z. W., Ong, S. E. C., Blattmann, P., and Thorp, T. G. (2012). Vascular functioning and the water balance of ripening kiwifruit (Actinidia chinensis) berries. J. Exp. Bot. 63, 1835-1847. doi: 10.1093/jxb/err352

Conn, S., and Gilliham, M. (2010). Comparative physiology of elemental distributions in plants. Ann. Bot. 105, 1081-1102. doi: 10.1093/aob/mcq027

Conn, S. J., Berninger, P., Broadley, M. R., and Gilliham, M. (2012). Exploiting natural variation to uncover candidate genes that control element accumulation in Arabidopsis thaliana. New Phytol. 193, 859-866. doi: 10.1111/j.14698137.2011.03977.x

Conn, S. J., Gilliham, M., Athman, A., Schreiber, A. W., Baumann, U., Moller, I., et al. (2011). Cell-specific vacuolar calcium storage mediated by CAX1 regulates apoplastic calcium concentration, gas exchange, and plant productivity in Arabidopsis. Plant Cell 23, 240-257. doi: 10.1105/tpc.109.072769

Coolong, T., Mishra, S., Barickman, C., and Sams, C. (2014). Impact of supplemental calcium chloride on yield, quality, nutrient status, and postharvest attributes of tomato. J. Plant Nutr. 37, 2316-2330. doi: 10.1080/01904167.2014.890222

Cramer, G., Urano, K., Delrot, S., Pezzotti, M., and Shinozaki, K. (2011). Effects of abiotic stress on plants: a systems biology perspective. BMC Plant Biol. 11:163 doi: 10.1186/1471-2229-11-163

Curvers, K., Seifi, H., Mouille, G., De Rycke, R., Asselbergh, B., Van Hecke, A., et al. (2010). Abscisic acid deficiency causes changes in cuticle permeability and pectin composition that influence tomato resistance to Botrytis cinerea. Plant Physiol. 154, 847-860. doi: 10.1104/pp.110.158972

Cybulska, J., Zdunek, A., and Konstankiewicz, K. (2011). Calcium effect on mechanical properties of model cell walls and apple tissue. J. Food Eng. 102, 217-223. doi: 10.1016/j.jfoodeng.2010.08.019

Dal Santo, S., Vannozzi, A., Tornielli, G. B., Fasoli, M., Venturini, L., Pezzotti, M., et al. (2013). Genome-wide analysis of the expansin gene superfamily reveals grapevine-specific structural and functional characteristics. PLoS ONE 8:e62206. doi: 10.1371/journal.pone.0062206

Dayod, M., Tyerman, S. D., Leigh, R. A., and Gilliham, M. (2010). Calcium storage in plants and the implications for calcium biofortification. Protoplasma 247, 215-231. doi: 10.1007/s00709-010-0182-0

de Freitas, S. T., Do Amarante, C. V. T., Dandekar, A. M., and Mitcham, E. J. (2013). Shading affects flesh calcium uptake and concentration, bitter pit incidence and other fruit traits in "Greensleeves" apple. Sci. Hortic. 161, 266-272. doi: 10.1016/j.scienta.2013.07.019

de Freitas, S. T., Jiang, C. Z., and Mitcham, E. J. (2012). Mechanisms involved in calcium deficiency development in tomato fruit in response to gibberellins. J. Plant Growth Regul. 31, 221-234. doi: 10.1007/s00344-011-9233-9

de Freitas, S. T., Mcelrone, A. J., Shackel, K. A., and Mitcham, E. J. (2014). Calcium partitioning and allocation and blossom-end rot development in tomato plants in response to whole-plant and fruit-specific abscisic acid treatments. J. Exp. Bot. 65, 235-247. doi: 10.1093/jxb/ert364

de Freitas, S. T., and Mitcham, E. J. (2012). "Factors involved in fruit calcium deficiency disorders," in Horticultural Reviews. (New York, NY: John Wiley \& Sons, Inc.), 107-146.

de Freitas, S. T., Padda, M., Wu, Q. Y., Park, S., and Mitcham, E. J. (2011). Dynamic alternations in cellular and molecular components during blossom-end rot development in tomatoes expressing sCAX1, a constitutively active $\mathrm{Ca} 2+/ \mathrm{H}+$ antiporter from Arabidopsis. Plant Physiol. 156, 844-855. doi: 10.1104/pp.111.175208

Decreux, A., and Messiaen, J. (2005). Wall-associated kinase WAK1 interacts with cell wall pectins in a calcium-induced conformation. Plant Cell Physiol. 46, 268-278. doi: 10.1093/pcp/pci026

Deluc, L. G., Quilici, D. R., Decendit, A., Grimplet, J., Wheatley, M. D., Schlauch, K. A., et al. (2009). Water deficit alters differentially metabolic pathways affecting important flavor and quality traits in grape berries of Cabernet Sauvignon and Chardonnay. BMC Genom. 10:212. doi: 10.1186/1471-216410-212

Deytieux, C., Geny, L., and Doneche, B. (2005). "Relation between hormonal balance and polygalacturonase activity in grape berry," in Proceedings of the 5th International Postharvest Symposium, Vol. 1-3, eds F. Mencarelli and P. Tonutti (Leuven 1: International Society Horticultural Science), 163-170. doi: 10.17660/actahortic.2005.682.15

Deytieux-Belleau, C., Vallet, A., Doneche, B., and Geny, L. (2008). Pectin methylesterase and polygalacturonase in the developing grape skin. Plant Physiol. Biochem. 46, 638-646. doi: 10.1016/j.plaphy.2008.04.008

Dodd, A. N., Kudla, J., and Sanders, D. (2010). The language of calcium signalling. Annu. Rev. Plant Biol. 61, 593-620. doi: 10.1146/annurev-arplant-070109104628

Dominguez, E., Lopez-Casado, G., Cuartero, J., and Heredia, A. (2008). Development of fruit cuticle in cherry tomato (Solanum lycopersicum). Funct. Plant Biol. 35, 403-411. doi: 10.1071/FP08018

Drazeta, L., Lang, A., Hall, A. J., Volz, R. K., and Jameson, P. E. (2004). Causes and effects of changes in xylem functionality in apple fruit. Ann. Bot. 93, 275-282. doi: 10.1093/aob/mch040

Espana, L., Heredia-Guerrero, J. A., Segado, P., Benitez, J. J., Heredia, A., and Dominguez, E. (2014). Biomechanical properties of the tomato (Solanum lycopersicum) fruit cuticle during development are modulated by changes in the relative amounts of its components. New Phytol. 202, 790-802. doi: $10.1111 / \mathrm{nph} .12727$

Evans, D. E., Briars, S. A., and Williams, L. E. (1991). Active calcium-transport by plant-cell membranes. J. Exp. Bot. 42, 285-303. doi: 10.1093/jxb/42.3.285

Fasoli, M., Dal Santo, S., Zenoni, S., Tornielli, G. B., Farina, L., Zamboni, A., et al. (2012). The grapevine expression atlas reveals a deep transcriptome shift driving the entire plant into a maturation program. Plant Cell 24, 3489-3505. doi: $10.1105 /$ tpc. 112.100230

Felle, H. H., Hanstein, S., Steinmeyer, R., and Hedrich, R. (2000). Dynamics of ionic activities in the apoplast of the sub-stomatal cavity of intact Vicia faba leaves during stomatal closure evoked by ABA and darkness. Plant J. 24, 297-304. doi: 10.1046/j.1365-313x.2000.00878.x

Ferguson, I. B. (1984). Calcium in plant senescence and fruit ripening. Plant Cell Environ. 7, 477-489. doi: 10.1111/j.1365-3040.1984.tb01438.x

Fortes, A. M., Teixeira, R. T., and Agudelo-Romero, P. (2015). Complex interplay of hormonal signals during grape berry ripening. Molecules 20, 9326-9343. doi: 10.3390/molecules20059326

Fozard, J. A., King, J. R., and Bennett, M. J. (2013). Modelling auxin efflux carrier phosphorylation and localization. J. Theoret. Biol. 319, 34-49. doi: 10.1016/j.jtbi.2012.11.011

Franceschi, V. R., and Nakata, P. A. (2005). Calcium oxalate in plants: formation and function. Annu. Rev. Plant Biol. 56, 41-71. doi: 10.1146/annurev.arplant.56.032604.144106 
Fritz, E. (2007). Measurement of cation exchange capacity (CEC) of plant cell walls by X-ray microanalysis (EDX) in the transmission electron microscope. Microsc. Microanal. 13, 233-244. doi: 10.1017/S1431927607070420

Fuentes, S., Ljung, K., Sorefan, K., Alvey, E., Harberd, N. P., and Ostergaard, L. (2012). Fruit growth in Arabidopsis occurs via DELLA-dependent and DELLA-independent gibberellin responses. Plant Cell 24, 3982-3996. doi: $10.1105 /$ tpc.112.103192

Fuentes, S., Sullivan, W., Tilbrook, J., and Tyerman, S. (2010). A novel analysis of grapevine berry tissue demonstrates a variety-dependent correlation between tissue vitality and berry shrivel. Aust. J. Grape Wine Res. 16, 327-336. doi: 10.1111/j.1755-0238.2010.00095.x

Gambetta, G. A., Matthews, M. A., Shaghasi, T. H., Mcelrone, A. J., and Castellarin, S. D. (2010). Sugar and abscisic acid signaling orthologs are activated at the onset of ripening in grape. Planta 232, 219-234. doi: 10.1007/s00425-0101165-2

Gendre, D., Mcfarlane, H. E., Johnson, E., Mouille, G., Sjodin, A., Oh, J., et al. (2013). Trans-Golgi network localized ECHIDNA/Ypt interacting protein complex is required for the secretion of cell wall polysaccharides in Arabidopsis. Plant Cell 25, 2633-2646. doi: 10.1105/tpc.113.112482

Gilliham, M., Athman, A., Tyerman, S. D., and Conn, S. J. (2011a). Cell-specific compartmentation of mineral nutrients is an essential mechanism for optimal plant productivity-another role for TPC1? Plant Signal. Behav. 6, 1656-1661. doi: $10.4161 /$ psb.6.11.17797

Gilliham, M., Dayod, M., Hocking, B. J., Xu, B., Conn, S. J., Kaiser, B. N., et al. (2011b). Calcium delivery and storage in plant leaves: exploring the link with water flow. J. Exp. Bot. 62, 2233-2250. doi: 10.1093/jxb/err111

Greenspan, M. D., Shackel, K. A., and Matthews, M. A. (1994). Developmentalchanges in the diurnal water-budget of the grape berry exposed to water deficits. Plant Cell Environ. 17, 811-820. doi: 10.1111/j.1365-3040.1994.tb00 175.x

Grignon, C., and Sentenac, H. (1991). pH and ionic conditions in the apoplast. Ann. Rev. Plant Physiol. 42, 103-128. doi: 10.1146/annurev.pp.42.060191.000535

Han, S. C., Tang, R. H., Anderson, L. K., Woerner, T. E., and Pei, Z. M. (2003). A cell surface receptor mediates extracellular Ca2+ sensing in guard cells. Nature 425, 196-200. doi: 10.1038/nature01932

Hayes, M. A., Davies, C., and Dry, I. B. (2007). Isolation, functional characterization, and expression analysis of grapevine (Vitis vinifera L.) hexose transporters: differential roles in sink and source tissues. J. Exp. Bot. 58, 1985-1997. doi: 10.1093/jxb/erm061

Hayes, M. A., Feechan, A., and Dry, I. B. (2010). Involvement of abscisic acid in the coordinated regulation of a stress-inducible hexose transporter (VvHT5) and a cell wall invertase in grapevine in response to biotrophic fungal infection. Plant Physiol. 153, 211-221. doi: 10.1104/pp.110.154765

Henderson, S. H., and Gilliham, M. (2015). "Cell-type specific molecular mechanisms of plant adaptation to abiotic stresses," in Mechanisms in Plant Adaptation, ed. R. Laitinen (London: Wiley Blackwell).

Hepler, P. K., and Winship, L. J. (2010). Calcium at the cell wall-cytoplast interface. J. Integr. Plant Biol. 52, 147-160. doi: 10.1111/j.1744-7909.2010.00923.x

Ho, L. C., Belda, R., Brown, M., Andrews, J., and Adams, P. (1993). Uptake and transport of calcium and the possible causes of blossom-end rot in tomato. J. Exp. Bot. 44, 509-518. doi: 10.1093/jxb/44.2.509

Ho, L. C., and White, P. J. (2005). A cellular hypothesis for the induction of blossom-end rot in tomato fruit. Ann. Bot. 95, 571-581. doi: $10.1093 / \mathrm{aob} / \mathrm{mci} 065$

Hocking, P. J. (1980). The composition of phloem exudate and xylem sap from tree tobacco (Nicotiana glauca Grah.). Ann. Bot. 45, 633-643.

Hoson, T. (1998). Apoplast as the site of response to environmental signals. J. Plant Res. 111, 167-177. doi: 10.1007/BF02507163

Jiang, L. X., Yang, S. L., Xie, L. F., Puah, C. S., Zhang, X. Q., Yang, W. C., et al. (2005). VANGUARD1 encodes a pectin methylesterase that enhances pollen tube growth in the Arabidopsis style and transmitting tract. Plant Cell 17, 584-596. doi: 10.1105/tpc.104.027631

Johnson, C. H., Knight, M. R., Kondo, T., Masson, P., Sedbrook, J., Haley, A., et al. (1995). Circadian oscillations of cytosolic and chloroplastic free calcium in plants. Science 269, 1863-1865. doi: 10.1126/science.7569925

Johnson, C. H., Shingles, R., and Ettinger, W. (2006). "Regulation and role of calcium fluxes in the chloroplast," in The Structure and Function of Plastids, eds R. Wise and J. Hoober. (Dordrecht: Springer), 403-416.
Karlova, R., Chapman, N., David, K., Angenent, G. C., Seymour, G. B., and De Maagd, R. A. (2014). Transcriptional control of fleshy fruit development and ripening. J. Exp. Bot. 65, 4527-4541. doi: 10.1093/jxb/eru316

Keller, M., and Shrestha, P. M. (2014). Solute accumulation differs in the vacuoles and apoplast of ripening grape berries. Planta 239, 633-642. doi: 10.1007/s00425-013-2004-Z

Keller, M., Zhang, Y., Shrestha, P. M., Biondi, M., and Bondada, B. R. (2015). Sugar demand of ripening grape berries leads to recycling of surplus phloem water via the xylem. Plant Cell Environ. 38, 1048-1059. doi: 10.1111/pce.12465

Kidman, C. M., Dry, P. R., Mccarthy, M. G., and Collins, C. (2014). Effect of rootstock on nutrition, pollination and fertilisation in 'Shiraz' (Vitis vinifera L.). Vitis 53, 139-145.

Kiegle, E., Moore, C. A., Haseloff, J., Tester, M. A., and Knight, M. R. (2000). Celltype-specific calcium responses to drought, salt and cold in the Arabidopsis root. Plant J. 23, 267-278. doi: 10.1046/j.1365-313x.2000.00786.x

Kim, K. N., Cheong, Y. H., Grant, J. J., Pandey, G. K., and Luan, S. (2003). CIPK3, a calcium sensor-associated protein kinase that regulates abscisic acid and cold signal transduction in Arabidopsis. Plant Cell 15, 411-423. doi: $10.1105 /$ tpc.006858

Knipfer, T., Fei, J., Gambetta, G. A., Mcelrone, A. J., Shackel, K. A., and Matthews, M. A. (2015). Water transport properties of the grape pedicel during fruit development: insights into xylem anatomy and function using microtomography. Plant Physiol. 168, 1590-1602. doi: 10.1104/pp.15.00031

Knoche, M., and Peschel, S. (2007). Gibberellins increase cuticle deposition in developing tomato fruit. Plant Growth Regul. 51, 1-10. doi: 10.1007/s10725006-9107-5

Kohorn, B. D., and Kohorn, S. L. (2012). The cell wall-associated kinases,WAKs, as pectin receptors. Front. Plant Sci. 3:88. doi: 10.3389/fpls.2012.00088.

Konrad, K. R., Wudick, M. M., and Feijo, J. A. (2011). Calcium regulation of tip growth: new genes for old mechanisms. Curr. Opin. Plant Biol. 14, 721-730. doi: 10.1016/j.pbi.2011.09.005

Krasnow, M., Matthews, M., and Shackel, K. (2008). Evidence for substantial maintenance of membrane integrity and cell viability in normally developing grape (Vitis vinifera L.) berries throughout development. J. Exp. Bot. 59, 849-859. doi: 10.1093/jxb/erm372

Kudla, J., Batistic, O., and Hashimoto, K. (2010). Calcium signals: the lead currency of plant information processing. Plant Cell 22, 541-563. doi: $10.1105 /$ tpc.109.072686

Kumar, R., Khurana, A., and Sharma, A. K. (2014). Role of plant hormones and their interplay in development and ripening of fleshy fruits. J. Exp. Bot. 65, 4561-4575. doi: 10.1093/jxb/eru277

Lacampagne, S., Lambert, C., Belleau-Deytieux, C., L'Hyvernay, A., Doneche, B., and Geny, L. (2010). "Expression, activity and cellular localization of pectin methylesterase in grape berry skin during ripening," in Proceedings of the Vi International Postharvest Symposium, eds M. Erkan and U. Aksoy (Leuven 1: Int Soc Horticultural Science), 1057-1062. doi: 10.17660/actahortic.2010.877.143

Lang, A., and Thorpe, M. R. (1989). Xylem, phloem and transpiration flows in a grape - application of a technique for measuring the volume of attached fruits to high-resolution using Archimedes principle. J. Exp. Bot. 40, 1069-1078. doi: $10.1093 / \mathrm{jxb} / 40.10 .1069$

Lee, K. J. D., Marcus, S. E., and Knox, J. P. (2011). Cell wall biology: perspectives from cell wall imaging. Mol. Plant 4, 212-219. doi: 10.1093/mp/ ssq075

Leng, P., Yuan, B., and Guo, Y. (2014). The role of abscisic acid in fruit ripening and responses to abiotic stress. J. Exp. Bot. 65, 4577-4588. doi: 10.1093/jxb/eru204

Leung, J., Bouvierdurand, M., Morris, P. C., Guerrier, D., Chefdor, F., and Giraudat, J. (1994). Arabidopsis ABA response gene ABI1 - features of a calcium-modulated protein phosphatase. Science 264, 1448-1452. doi: 10.1126/science.7910981

Lu, Y. Q., Liu, H. P., Wang, Y., Zhang, X. Z., and Han, Z. H. (2013). Synergistic roles of leaf boron and calcium during the growing season in affecting sugar and starch accumulation in ripening apple fruit. Acta Physiol. Plant. 35, 2483-2492. doi: 10.1007/s11738-013-1283-0

Madrid, R., Valverde, M., Alcolea, V., and Romojaro, F. (2004). Influence of calcium nutrition on water soaking disorder during ripening of Cantaloupe melon. Sci. Hortic. 101, 69-79. doi: 10.1016/j.scienta.2003.10.005

Manganaris, G. A., Vasilakakis, M., Mignani, I., Diamantidis, G., and TzavellaKlonari, K. (2005). The effect of preharvest calcium sprays on quality attributes, 
physicochemical aspects of cell wall components and susceptibility to brown rot of peach fruits (Prunus persica L. cv. Andross). Sci. Hortic. 107, 43-50. doi: 10.1016/j.scienta.2005.06.005

Marti, M. C., Stancombe, M. A., and Webb, A. A. R. (2013). Cell- and stimulus type-specific intracellular free Ca2+ signals in Arabidopsis. Plant Physiol. 163, 625-634. doi: 10.1104/pp.113.222901

Martin, L. B. B., and Rose, J. K. C. (2014). There's more than one way to skin a fruit: formation and functions of fruit cuticles. J. Exp. Bot. 65, 4639-4651. doi: $10.1093 / \mathrm{jxb} / \mathrm{eru} 301$

Marzouk, H. A., and Kassem, H. A. (2011). Improving yield, quality, and shelf life of Thompson seedless grapevine by preharvest foliar applications. Sci. Hortic.130, 425-430. doi: 10.1016/j.scienta.2011.07.013

Matthews, M. A., Thomas, T. R., and Shackel, K. A. (2009). Fruit ripening in Vitis vinifera L.: possible relation of veraison to turgor and berry softening. Aust. J. Grape Wine Res. 15, 278-283. doi: 10.1111/j.1755-0238.2009.00060.x

Mazzeo, M., Dichio, B., Clearwater, M. J., Montanaro, G., and Xiloyannis, C. (2013). Hydraulic resistance of developing Actinidia fruit. Ann. Bot. 112, 197-205. doi: 10.1093/aob/mct101

McAinsh, M. R., and Pittman, J. K. (2009). Shaping the calcium signature. New Phytol. 181, 275-294. doi: 10.1111/j.1469-8137.2008.02682.x

McAtee, P., Karim, S., Schaffer, R., and David, K. (2013). A dynamic interplay between phytohormones is required for fruit development, maturation, and ripening. Front. Plant Sci. 4:79. doi: 10.3389/fpls.2013.00079.

Michard, E., Dias, P., and Feijo, J. A. (2008). Tobacco pollen tubes as cellular models for ion dynamics: improved spatial and temporal resolution of extracellular flux and free cytosolic concentration of calcium and protons using pHluorin and YC3.1 CaMeleon. Sex. Plant Reprod. 21, 169-181. doi: 10.1007/s00497-008-0076-x

Mohnen, D. (2008). Pectin structure and biosynthesis. Curr. Opin. Plant Biol. 11, 266-277. doi: 10.1016/j.pbi.2008.03.006

Montanaro, G., Dichio, B., Lang, A., Mininni, A. N., Nuzzo, V., Clearwater, M. J., et al. (2014). Internal versus external control of calcium nutrition in kiwifruit. J. Plant Nutr. Soil Sci. 177, 819-830. doi: 10.1002/jpln.201400396

Montanaro, G., Dichio, B., Lang, A., Mininni, A. N., and Xiloyannis, C. (2015). Fruit calcium accumulation coupled and uncoupled from its transpiration in kiwifruit. J. Plant Physiol. 181, 67-74. doi: 10.1016/j.jplph.2015.04.004

Montanaro, G., Dichio, B., Xiloyannis, C. (2012a). "Fruit transpiration: mechanisms and significance for fruit nutrition and growth," in Advances in Selected Plant Physiology Aspects, ed. G Montanaro (Rijeka: Intech),

Montanaro, G., Dichio, B., Xiloyannis, C., and Lang, A. (2012b). Fruit transpirationin kiwifruit: environmental drivers and predictive model. $A o B$ Plants 6, pls036. doi: 10.1093/aobpla/pls036

Montanaro, G., Treutter, D., and Xiloyannis, C. (2007). Phenolic compounds in young developing kiwifruit in relation to light exposure: implications for fruit calcium accumulation. J. Plant Interact. 2, 63-69. doi: $10.1080 / 17429140701429228$

Nawrath, C., Schreiber, L., Franke, R. B., Geldner, N., Reina-Pinto, J. J., and Kunst, L. (2013). Apoplastic diffusion barriers in Arabidopsis. Arabidopsis Book 11, e0167. doi: 10.1199/tab.0167

Ngouemazong, D. E., Jolei, R. P., Cardinaels, R., Fraeye, I., Van Loey, A., Moldenaers, P., et al. (2012). Stiffness of $\mathrm{Ca}^{2+}$-pectin gels: combined effects of degree and pattern of methylesterification for various $\mathrm{Ca}^{2+}$ concentrations. Carbohydr. Res. 348, 69-76. doi: 10.1016/j.carres.2011.11.011

Nicolas, P., Lecourieux, D., Kappel, C., Cluzet, S., Cramer, G., Delrot, S., et al. (2014). The basic leucine zipper transcription factor ABSCISIC ACID RESPONSE ELEMENT-BINDING FACTOR2 is an important transcriptional regulator of abscisic acid-dependent grape berry ripening processes. Plant Phys. 164, 365-383. doi: 10.1104/pp.113.231977

Nishizawa, T., Kobayashi, T., and Aikawa, T. (2004). Effect of calcium supply on the physiology of fruit tissue in 'Andesu' netted melon. J. Hortic. Sci. Biotechnol. 79, 500-508. doi: 10.1080/14620316.2004.11511796

Nunan, K. J., Davies, C., Robinson, S. P., and Fincher, G. B. (2001). Expression patterns of cell wall-modifying enzymes during grape berry development. Planta 214, 257-264. doi: 10.1007/s004250100609

Nunan, K. J., Sims, I. M., Bacic, A., Robinson, S. P., and Fincher, G. B. (1998). Changes in cell wall composition during ripening of grape berries. Plant Physiol. 118, 783-792. doi: 10.1104/pp.118.3.783
Ortega-Regules, A., Ros-Garcia, J. M., Bautista-Ortin, A. B., Lopez-Roca, J. M., and Gomez-Plaza, E. (2008). Changes in skin cell wall composition during the maturation of four premium wine grape varieties. J. Sci. Food Agric. 88, 420-428. doi: $10.1002 /$ jsfa. 3102

Osorio, S., Castillejo, C., Quesada, M. A., Medina-Escobar, N., Brownsey, G. J., Suau, R., et al. (2008). Partial demethylation of oligogalacturonides by pectin methyl esterase 1 is required for eliciting defence responses in wild strawberry (Fragaria vesca). Plant J. 54, 43-55. doi: 10.1111/j.1365-313X.2007. 03398.x

Osorio, S., Scossa, F., and Fernie, A. R. (2013). Molecular regulation of fruit ripening. Front. Plant Sci. 4:198. doi: 10.3389/fpls.2013.00198

Palumbo, M. C., Zenoni, S., Fasoli, M., Massonnet, M., Farina, L., Castiglione, F., et al. (2014). Integrated network analysis identifies fight-club nodes as a class of hubs encompassing key putative switch genes that induce major transcriptome reprogramming during grapevine development. Plant Cell 26, 4617-4635. doi: $10.1105 /$ tpc. 114.133710

Pan, Q. H., Li, M. J., Peng, C. C., Zhang, N., Zou, X., Zou, K. Q., et al. (2005). Abscisic acid activates acid invertases in developing grape berry. Physiol. Plant. 125, 157-170. doi: 10.1111/j.1399-3054.2005.00552.x

Pandey, G. K., Cheong, Y. H., Kim, K. N., Grant, J. J., Li, L. G., Hung, W., et al. (2004). The calcium sensor calcineurin B-Like 9 modulates abscisic acid sensitivity and biosynthesis in Arabidopsis. Plant Cell 16, 1912-1924. doi: $10.1105 /$ tpc.021311

Park, S., Cheng, N. H., Pittman, J. K., Yoo, K. S., Park, J., Smith, R. H., et al. (2005). Increased calcium levels and prolonged shelf life in tomatoes expressing Arabidopsis H+/Ca2+ transporters. Plant Physiol. 139, 1194-1206. doi: $10.1104 /$ pp.105.066266

Pilati, S., Brazzale, D., Guella, G., Milli, A., Ruberti, C., Biasioli, F., et al. (2014). The onset of grapevine berry ripening is characterized by ROS accumulation and lipoxygenase-mediated membrane peroxidation in the skin. BMC Plant Biol. 14:87. doi: $10.1186 / 1471-2229-14-87$

Pitann, B., Schubert, S., and Muehling, K. H. (2009). Decline in leaf growth under salt stress is due to an inhibition of $\mathrm{H}+$-pumping activity and increase in apoplastic pH of maize leaves. J. Plant Nutr. Soil Sc. 172, 535-543. doi: 10.1002/jpln.200800349

Plavcova, L., and Hacke, U. G. (2011). Heterogeneous distribution of pectin epitopes and calcium in different pit types of four angiosperm species. New Phytol. 192, 885-897. doi: 10.1111/j.1469-8137.2011. 03842.x

Redgwell, R. J., Macrae, E., Hallett, I., Fischer, M., Perry, J., and Harker, R. (1997). In vivo and in vitro swelling of cell walls during fruit ripening. Planta 203, 162-173. doi: $10.1007 / \mathrm{s} 004250050178$

Rober-Kleber, N., Albrechtova, J. T. P., Fleig, S., Huck, N., Michalke, W., Wagner, E., et al. (2003). Plasma membrane $\mathrm{H}^{+}$-ATPase is involved in auxinmediated cell elongation during wheat embryo development. Plant Physiol. 131, 1302-1312. doi: 10.1104/pp.013466

Rogiers, S. Y., Greer, D. H., Hatfield, J. M., Orchard, B. A., and Keller, M. (2006a). Mineral sinks within ripening grape berries (Vitis vinifera L.). Vitis 45, 115-123.

Rogiers, S. Y., Greer, D. H., Hatfield, J. M., Orchard, B. A., and Keller, M. (2006b). Solute transport into Shiraz berries during development and late-ripening shrinkage. Am. J. Enol. Vitic. 57, 73-80.

Rogiers, S. Y., Keller, M., Holzapfel, B. P., and Virgona, J. M. (2000). Accumulation of potassium and calcium by ripening berries on field vines of Vitis vinifera (L) cv, Shiraz. Aust. J. Grape Wine Res. 6, 240-243. doi: 10.1111/j.17550238.2000.tb00184.x

Rounds, C. M., Lubeck, E., Hepler, P. K., and Winship, L. J. (2011). Propidium iodide competes with $\mathrm{Ca}^{2+}$ to label pectin in pollen tubes and Arabidopsis root hairs. Plant Physiol. 157, 175-187. doi: 10.1104/pp.111.182196

Ruan, Y. L., Patrick, J. W., Bouzayen, M., Osorio, S., and Fernie, A. R. (2012). Molecular regulation of seed and fruit set. Trends Plant Sci. 17, 656-665. doi: 10.1016/j.tplants.2012.06.005

Saladie, M., Matas, A. J., Isaacson, T., Jenks, M. A., Goodwin, S. M., Niklas, K. J., et al. (2007). A reevaluation of the key factors that influence tomato fruit softening and integrity. Plant Physiol. 144, 1012-1028. doi: 10.1104/pp.107.097477

Sampedro, J., and Cosgrove, D. J. (2005). The expansin superfamily. Genome Biol. 6. 242. doi: 10.1186/gb-2005-6-12-242 
Sato, S., Tabata, S., Hirakawa, H., Asamizu, E., Shirasawa, K., Isobe, S., et al. (2012). The tomato genome sequence provides insights into fleshy fruit evolution. Nature 485, 635-641. doi: 10.1038/nature11119

Saure, M. C. (2005). Calcium translocation to fleshy fruit: its mechanism and endogenous control. Scientia Hortic. 105, 65-89. doi: $10.1016 /$ j.scienta.2004.10.003

Saure, M. C. (2014). Why calcium deficiency is not the cause of blossom-end rot in tomato and pepper fruit - a reappraisal. Sci. Hortic. 174, 151-154. doi: 10.1016/j.scienta.2014.05.020

Schlosser, J., Olsson, N., Weis, M., Reid, K., Peng, F., Lund, S., et al. (2008). Cellular expansion and gene expression in the developing grape (Vitis vinifera L.). Protoplasma 232, 255-265. doi: 10.1007/s00709-008-0280-9

Seifert, G. J., and Blaukopf, C. (2010). Irritable walls: the plant extracellular matrix and signaling. Plant Physiol. 153, 467-478. doi: 10.1104/pp.110.153940

Serrani, J. C., Ruiz-Rivero, O., Fos, M., and Garcia-Martinez, J. L. (2008). Auxininduced fruit-set in tomato is mediated in part by gibberellins. Plant J. 56, 922-934. doi: 10.1111/j.1365-313X.2008.03654.x

Shabala, S. (2000). Ionic and osmotic components of salt stress specifically modulate net ion fluxes from bean leaf mesophyll. Plant Cell Environ. 23, 825-837. doi: 10.1046/j.1365-3040.2000.00606.x

Shishova, M., and Lindberg, S. (2010). A new perspective on auxin perception. J. Plant Physiol. 167, 417-422. doi: 10.1016/j.jplph.2009.12.014

Sun, L., Sun, Y. F., Zhang, M., Wang, L., Ren, J., Cui, M. M., et al. (2012). Suppression of 9-cis-epoxycarotenoid dioxygenase, which encodes a key enzyme in abscisic acid biosynthesis, alters fruit texture in transgenic tomato. Plant Physiol. 158, 283-298. doi: 10.1104/pp.111.186866

Swarbreck, S. M., Colaco, R., and Davies, J. M. (2013). Plant calcium-permeable channels. Plant Physiol. 163, 514-522. doi: 10.1104/pp.113.220855

Tang, R. H., Han, S. C., Zheng, H. L., Cook, C. W., Choi, C. S., Woerner, T. E., et al. (2007). Coupling diurnal cytosolic Ca2+ oscillations to the CAS-IP3 pathway in Arabidopsis. Science 315, 1423-1426. doi: 10.1126/science.1134457

Thomas, T. R., Matthews, M. A., and Shackel, K. A. (2006). Direct in situ measurement of cell turgor in grape (Vitis vinifera L.) berries during development and in response to plant water deficits. Plant Cell Environ. 29, 993-1001. doi: 10.1111/j.1365-3040.2006.01496.x

Tibbits, C. W., Macdougall, A. J., and Ring, S. G. (1998). Calcium binding and swelling behaviour of a high methoxyl pectin gel. Carbohydr. Res. 310, 101-107. doi: 10.1016/S0008-6215(98)00172-4

Tilbrook, J., and Tyerman, S. D. (2009). Hydraulic connection of grape berries to the vine: varietal differences in water conductance into and out of berries, and potential for backflow. Funct. Plant Biol. 36, 541-550. doi: 10.1071/FP09019

Tyerman, S. D., Tilbrook, J., Pardo, C., Kotula, L., Sullivan, W., and Steudle, E. (2004). Direct measurement of hydraulic properties in developing berries of Vitis vinifera L. cv Shiraz and Chardonnay. Aust. J. Grape Wine Res. 10, 170-181. doi: 10.1111/j.1755-0238.2004.tb00020.x

Vallarino, J. G., and Osorio, S. (2012). Signaling role of oligogalacturonides derived during cell wall degradation. Plant Signal. Behav. 7, 1447-1449. doi: $10.4161 /$ psb. 21779

van Doorn, W. G., Hiemstra, T., and Fanourakis, D. (2011). Hydrogel regulation of xylem water flow: an alternative hypothesis. Plant Physiol. 157, 1642-1649. doi: 10.1104/pp.111.185314

Verdoucq, L., Grondin, A., and Maurel, C. (2008). Structure-function analysis of plant aquaporin AtPIP2;1 gating by divalent cations and protons. Biochem. J. 415, 409-416. doi: 10.1042/BJ20080275
Vorwerk, S., Somerville, S., and Somerville, C. (2004). The role of plant cell wall polysaccharide composition in disease resistance. Trends Plant Sci. 9, 203-209. doi: 10.1016/j.tplants.2004.02.005

Wang, L., and Ruan, Y. L. (2013). Regulation of cell division and expansion by sugar and auxin signaling. Front. Plant Sci. 4:163. doi: 10.3389/fpls.2013.00163

Wang, W. H., Chen, J., Liu, T. W., Chen, J., Han, A. D., Simon, M., et al. (2014). Regulation of the calcium-sensing receptor in both stomatal movement and photosynthetic electron transport is crucial for water use efficiency and drought tolerance in Arabidopsis. J. Exp. Bot. 65, 223-234. doi: 10.1093/jxb/ert362

Wang, W. H., Yi, X. Q., Han, A. D., Liu, T. W., Chen, J., Wu, F. H., et al. (2012). Calcium-sensing receptor regulates stomatal closure through hydrogen peroxide and nitric oxide in response to extracellular calcium in Arabidopsis. J. Exp. Bot. 63, 177-190. doi: 10.1093/jxb/err259

Webb, A. A. R., Larman, M. G., Montgomery, L. T., Taylor, J. E., and Hetherington, A. M. (2001). The role of calcium in ABA-induced gene expression and stomatal movements. Plant J. 26, 351-362. doi: 10.1046/j.1365-313X.2001.01032.x

Whalley, H. J., and Knight, M. R. (2013). Calcium signatures are decoded by plants to give specific gene responses. New Phytol. 197, 690-693. doi: $10.1111 / \mathrm{nph} .12087$

White, P. J. (2000). Calcium channels in higher plants. BBA-Biomembranes 1465, 171-189. doi: 10.1016/S0005-2736(00)00137-1

White, P. J. (2001). The pathways of calcium movement to the xylem. J. Exp. Bot. 52, 891-899. doi: 10.1093/jexbot/52.358.891

White, P. J., and Broadley, M. R. (2003). Calcium in plants. Ann. Bot. 92, 487-511. doi: $10.1093 / \mathrm{aob} / \mathrm{mcg} 164$

Willats, W. G. T., Orfila, C., Limberg, G., Buchholt, H. C., Van Alebeek, G., Voragen, A. G. J., et al. (2001). Modulation of the degree and pattern of methylesterification of pectic homogalacturonan in plant cell walls - implications for pectin methyl esterase action, matrix properties, and cell adhesion. J. Biol. Chem. 276, 19404-19413. doi: 10.1074/jbc.M011242200

Yu, X. C., Li, M. J., Gao, G. F., Feng, H. Z., Geng, X. Q., Peng, C. C., et al. (2006). Abscisic acid stimulates a calcium-dependent protein kinase in grape berry. Plant Physiol. 140, 558-579. doi: 10.1104/pp.105.074971

Zhu, S. Y., Yu, X. C., Wang, X. J., Zhao, R., Li, Y., Fan, R. C., et al. (2007). Two calcium-dependent protein kinases, CPK4 and CPK11, regulate abscisic acid signal transduction in Arabidopsis. Plant Cell 19, 3019-3036. doi: 10.1105/tpc.107.050666

Zsivanovits, G., Macdougall, A. J., Smith, A. C., and Ring, S. G. (2004). Material properties of concentrated pectin networks. Carbohydr. Res. 339, 1317-1322. doi: 10.1016/j.carres.2004.02.027

Zwieniecki, M. A., Melcher, P. J., and Holbrook, N. M. (2001). Hydrogel control of xylem hydraulic resistance in plants. Science 291, 1059-1062. doi: $10.1126 /$ science. 1057175

Conflict of Interest Statement: The authors declare that the research was conducted in the absence of any commercial or financial relationships that could be construed as a potential conflict of interest.

Copyright (c) 2016 Hocking, Tyerman, Burton and Gilliham. This is an open-access article distributed under the terms of the Creative Commons Attribution License (CC BY). The use, distribution or reproduction in other forums is permitted, provided the original author(s) or licensor are credited and that the original publication in this journal is cited, in accordance with accepted academic practice. No use, distribution or reproduction is permitted which does not comply with these terms. 